Article

\title{
Can Road Toll Convince Car Travelers to Adjust Their Departure Times? Accounting for the Effect of Choice Behavior under Long and Short Holidays
}

\author{
Haiyan Zhu ${ }^{1,2} \mathbb{D}^{\text {, Hongzhi Guan }}{ }^{1}$, Yan Han ${ }^{1, * \mathbb{D}}$ and Wanying $\mathrm{Li}^{1}$ \\ 1 College of Architecture and Civil Engineering, Beijing University of Technology, Beijing 100124, China; \\ zzhaiyan1213@126.com (H.Z.); hguan@bjut.edu.cn (H.G.); liwanying@emails.bjut.edu.cn (W.L.) \\ 2 School of Civil and Traffic Engineering, Qinghai Nationalities University, Xining 810007, China \\ * Correspondence: hanyan422@bjut.edu.cn
}

Received: 16 October 2020; Accepted: 1 December 2020; Published: 15 December 2020

\begin{abstract}
The adjustment of road toll is an important measure that can alleviate road traffic congestion by convincing car travelers to travel during off-peak times. In order to reduce congestion on the expressway on the first day of a holiday, factors that affect the departure times of holiday travelers must be comprehensively understood to determine the best strategy to persuade car travelers to avoid peak travel times. This paper takes holiday car travelers as the research object and explores the characteristics and rules of departure time choice behavior for different holiday lengths. Based on Utility Maximization Theory, a multinomial logit (MNL) model of departure time choice for a three-day short holiday and a seven-day long holiday was established. Model calibration and elastic analysis were carried out using Revealed Preference/Stated Preference (RP/SP) survey data. Additionally, the influence of the highway toll policy on departure times for long and short holidays was analyzed. The results show that the rate of first-day departures is much higher than that of other departure times for both short and long vacations under the current policy of free holiday passage on highways. Factors such as trip duration, size of the tourist group, the number of visits, travel range, travel time, monthly income, occupation, age and road toll have a significant influence on the departure time decisions of holiday car travelers, and the effect and degree of influence are markedly different for different holiday lengths. The effects of tolls for each departure time and different pricing scenarios on the choice behavior of travelers are different between long and short holidays. Furthermore, the effectiveness of the road toll policy also varies for travelers with different travel distances. This study can provide useful information for the guidance of holiday travelers, the management of holiday tolls on expressways and the formulation of holiday leave time.
\end{abstract}

Keywords: holiday travel behavior; departure time; long and short holidays; road toll; car travelers; multinomial logit model

\section{Introduction}

China's statutory holidays have been adjusted several times to form a number of long and short consecutive holidays. Currently, China's seven statutory holidays are divided into three-day short holidays (hereinafter referred to as short holidays, including New Year's Day, Tomb Sweeping Day, Labor Day, Dragon Boat Festival and Mid-Autumn Festival) and seven-day "golden weeks" (hereinafter referred to as long holidays, including National Day and Spring Festival), and holiday tourism has become an important part of Chinese people's lives [1,2]. In recent years, with the improvement in people's living standards and the implementation of the free passage policy for minibuses on the expressway during important public holidays, the tourism demand has become very 
high, and it is concentrated during holidays [3,4]. In 2019, only 29 days of statutory holiday tourism accounted for $30 \%$ of the annual tourism market, and the number of domestic travelers amounted to 1.84 billion people, including $34.9 \%$ on short holidays and $65.1 \%$ on long holidays (values are from the collation of network open data). Since the implementation of the holiday highway free policy in 2012, self-driving travel has been increasing every year, with an average annual growth rate of $21.09 \%$. The total traffic volume on the highway has increased significantly, which has aggravated its congestion [2], increased air pollution by $20 \%$ and reduced visibility by $1 \mathrm{~km}$ [5].

According to the observation results of holiday traffic volume, the traffic pressure on domestic roads multiplies during holidays, the passenger flow in scenic spots reaches its peak, and expressway traffic represents a significant bottleneck [6,7]. Whether it is a three-day short holiday or a seven-day long holiday, the peaks of highway traffic due to departures and returns are mostly concentrated on the first day and the last day of the holiday. Usually, the highway traffic volume on short holidays is 2-3 times that on weekdays, and during long vacation periods, it is 4-6 times that on weekdays, with the most prominent peak congestion on the first day of holidays [7]. The constraint of limited holiday time and the appeal of the free passage policy results in the concentration of travel in a short period of time, exerting great pressure on road traffic, which frequently leads to highway congestion $[8,9]$. For example, in 2017, the five most congested expressways in the Pearl River Delta and the Yangtze River Delta were backed up for $24 \mathrm{~h}$ on the first day, the Beijing-Tianjin-Hebei region was congested for 11-13 h, and the Chengdu-Chongqing region was backed up for more than $14 \mathrm{~h} \mathrm{[6].} \mathrm{These} \mathrm{phenomena}$ not only affect the holiday travel experience of travelers, reduce travel efficiency, cause environmental pollution and lead to serious social problems but also restrict the sustainable development of tourism in the long run.

From the perspective of travel regulation and scenic spot management, people adopt methods such as holiday travel induction, vehicle type restriction, flow diversion at scenic spots, peak travel fares and advanced booking to adjust holiday passenger flow and alleviate the problem of holiday travel congestion $[1,3,10]$. However, in terms of results, the effects of these measures are very limited because people's travel times are highly concentrated. Many research institutions and data information platforms provide travel references for tourists by issuing holiday travel forecast reports to encourage them to travel at off-peak times. However, in the face of surges in travel on holidays, the alleviating effect on holiday congestion is very limited. On the one hand, this reflects the strong demand for tourism due to increasing living standards. On the other hand, it reflects the concentration of travel within a short period of time during holidays, which leads to a shortage of service facilities such as roads and scenic spots. Such a serious mismatch between the demand and supply of holiday travel, in addition to insufficient road traffic and scenic infrastructure, is also attributed to the over-concentrated travel time of tourists, which is largely the result of choices of departure times. Therefore, it is urgent to characterize the travel demand of holiday tourists, especially their departure time choice behavior, in order to solve the problem of holiday traffic congestion.

Departure time choice is an important topic in travel behavior research [2]. Time usually mainly includes year, month, day, hour, minute. Among them, hours as the division unit of time in commuting travel is the most common. The choice of departure time for holidays is different from that for daily commuting $[2,3,11]$. First of all, the time scale is different. The departure time in commuting is time-of-day choice (mostly in hours), and the departure time of holidays is the time choice within or outside the holiday cycle (mostly in days). Secondly, the restriction conditions of departure time choice are different. Commuting travel is mainly restricted by work or school time, while holiday travel is mainly restricted by free time (holiday). Moreover, the purpose and intention of choice behavior are different. Commuters is more for the purpose of going to work or going to school, and pay more attention to punctuality. However, holiday travelers mainly focusing on leisure and entertainment, vacation and family visit, etc., and pay more attention to travel experience. This paper focuses on the behavior of holiday departure time choice on a time scale of days. 
Access to road toll is an effective measure to regulate traffic demand and alleviate traffic congestion [12,13]. On the one hand, road toll can increase revenue for the construction and maintenance of infrastructure (e.g., European countries such as Spain, France and Poland, and Asian countries such as China, Japan and South Korea [8]). On the other hand, it can guide travel behavior to adjust the peak of traffic demand. For example, countries such as Singapore, Hong Kong and the Netherlands have adjusted peak demand well through road toll [14]. In addition, public holidays are usually faced with extremely high travel demand, so reducing the toll of existing toll roads to balance different demand is also a widely used transport demand measure. Specific measurements include setting a highway toll ceiling [15], implementing preferential policies for electronic payment vehicles in Japan and Malaysia [16], and giving private cars free passage in China and South Korea [5]. Therefore, adjusting the travel behavior of holiday travelers through road toll measures can be regarded as a countermeasure to alleviate holiday traffic congestion.

This paper aims to explore the possibility of using road toll to induce changes in the departure times of car travelers on holidays of different lengths. So as to provide a basis for making traffic management policies to calm travel demand and alleviate traffic congestion during holidays. Therefore, based on behavioral survey data, a multinomial logit model (MNL) model was constructed to analyze the departure time choice behavior characteristics of car travelers on long and short vacations, and evaluate the impact of road toll on travel demand.

The remaining sections are organized as follows: Section 2 briefly reviews the literature on holiday travel and departure time choice behaviors. Section 3 presents the research and investigation methodology. Section 4 analyzes the travel data of holiday travelers and constructs departure time choice models of short and long vacations based on the MNL model. Section 5 discusses the results of the model estimation. Finally, the main conclusions and future research work are summarized.

\section{Literature Review}

\subsection{Travel Behavior during Holidays}

In recent years, the increasingly prominent holiday travel problem has attracted the attention of many scholars [17-19]. Holiday travel behavior has been found to be very different from commuting behavior. Holiday travelers are usually more sensitive to changes in travel time and more dependent on cars $[11,20]$. The existing research on holiday travel choice behavior mainly focuses on travel mode [9,20,21], travel destination [22-24], travel time [11,25], parking choice [26], departure time, combined travel mode and travel destination choice behavior [27-29] and so on. In these studies, discrete choice models were used as the modeling method [30-32].

The characteristic variables related to holiday travel behavior mainly include social demographic characteristics, destination attributes, travel-related attributes (travel distance, travel mode, travel cost, etc.), tour characteristics (number of visitors, frequency of visits, etc.), information obtained and environmental and psychological factors $[10,23,33,34]$. Shailes et al. [35] showed that attitude, group size and visit frequency were the main factors that influenced holiday travel behavior. Wang et al. [9] used structural equation model to verify the influence of multivariate information on holiday travel behavior. Guan et al. [36] compared and studied self-driving travel behaviors in China and Beijing, and they found that income was the main influencing factor. Some studies have also proved the influence of psychological factors on holiday travel behavior [5,20,33].

A number of studies have also shown that the "holiday" itself has an impact on holiday travel behavior. For example, Cools' [37-39] studies have proved that public holidays have a non-negligible impact on travel behavior and suggested that the holiday effect be included in the travel behavior model. Mussalam et al. [40] discussed the relationship between destination attributes and a passenger's choice of a short or long vacation in Switzerland. They found that traffic efficiency was the most important factor in choosing a short vacation, and location was the most important factor in a long vacation. Wen et al. [11] studied the factors that influence the choice of the departure and return times 
of air passengers during a long vacation, and the results showed that the price of air tickets and the number of vacation days had a significant impact. Zhang et al. [41] hypothesized that the vacation system was an important factor that affected the travel time of urban residents. They analyzed and compared the changing rules of passenger flow at heritage sites in different periods of China's vacation system and concluded that the centralized trend of vacation time increased the passenger flow in that period.

In addition, some studies have explored holiday travel behavior from the perspective of the impact of the external environment or policy on behavior. Shailes et al. [35] showed that about $54 \%$ of holiday travelers chose to change their departure times in order to avoid congestion during peak traffic. Bao et al. [2] used the bottleneck model to evaluate the impact of a public holiday fee-free transportation policy on the departure time choice of holiday travelers from the perspective of theoretical model derivation. The results showed that the holiday fee-free policy did not always reduce the travel cost of holiday travelers, but it could definitely increase the total social cost. Lin et al. $[8,27,42]$ explored the influence mechanism of an expressway tolling policy on intercity travelers' choice of transportation mode during holidays from static and dynamic perspectives. Huang et al. [43], on the basis of expectation-titer theory and planned behavior theory, constructed a model of the relationship between a toll-free policy and changes in travel intentions during holidays to reveal the mechanism of action through which different variables affect travel intention. Qian et al. [44] used a structural equation model to explore the influence of toll-free expressway policy support on holiday travel behavior, and the results showed that people's support for the policy and their travel behaviors were mainly influenced by the travel quality, safety and public serviceability.

In general, the research on holiday travel behavior has focused on the study of transportation modes and destinations, and the exploration of the departure time choice behavior of holiday travelers has been largely insufficient. Although the influence of road toll on daily urban commuters has been widely discussed [45-47], there has been a lack of attention to the choice of departure times of holiday travelers.

\subsection{Departure Time Choice Behavior}

Previous studies in the literature have discussed the departure time choice behavior of commuters, and the research methods are mainly based on random utility theory, prospect theory and regret theory, among which the discrete choice model based on random utility theory has been the most widely used [48]. In addition, from the perspective of bounded rationality, some scholars have characterized the difficulty in making rational decisions under the influence of uncertain conditions and complex environments in studies on departure time behavior [49,50].

These studies have shown that the main influencing factors of departure time decisions include personal and family attributes, destination attributes, travel time, cost, travel purpose, the traveler's personality, psychological factors, the external environment and policies, etc. [51-53]. In their study on departure time choice behavior, Small et al. [51] used MNL model to explore the influence of working time, family conditions and travel time on the departure time choice behavior of car travelers. Bhat and Steed [54] established a discrete choice model from the perspective of traveling for leisure, entertainment and shopping. Studies have shown that sociodemographic variables, family structure variables, individual work-related attributes and travel characteristics all have significant effects on the departure times of travelers. Peter et al. [55] established an MNL model to study the impact of parking conditions at the destination, travel time and other factors on the choice of travel time for car travelers. Choo et al. [56] showed that travel preferences and attitudes had a significant impact on the departure time choice behavior of commuters. Engelson et al. [57] used the scheduling model of departure time choice to assess the value of travel time information from the perspective of an individual traveler.

Some studies have reported that changes in the external environment or policies have different degrees of influence on departure time decision-making, such as work systems, vacation systems, fare concessions, congestion charging, incentive policies and so on [58-60]. He et al. [61] conducted a 
comparative study on commuters in Los Angeles and San Francisco to explore the impact of a flexible working schedule on the departure time of commuters. The results showed that flexible working hours affected commuters' departure times, and commuters with flexible working hours were more likely to leave after peak hours. Ben-Elia et al. $[14,62,63]$ compared the impact of two congestion management schemes-road pricing and off-peak travel incentives-on car commuting behavior, and the incentive scheme was more effective in enabling commuters to avoid rush hours. Zhang et al. [64] constructed a probit model to test the impact of incentive measures and personal characteristics on the commuting departure time behavior of subway passengers. Pluntke et al. [65] and Currie [66] investigated the impact of public transport's implementation of a peak-free travel scheme on departure time behavior.

In sum, most of the research on departure time choice behavior has focused on daily commuting, while there have been few studies on holiday travel departure times, let alone empirical research on holiday travel in China.

Therefore, exploring the characteristics of travelers' behavioral decision-making with regard to departure times can fill in the gaps of existing studies, and understanding the influence of holiday road toll on travel behavior can help in the formulation of holiday traffic policies, holiday toll strategies and holiday vacation time.

\section{Methodology}

\subsection{Modeling Method}

Discrete choice models play an important role in travel behavior choice research [30]. Widely used are multinomial logit (MNL) model, nested logit (NL) model, mixed logit model, and so on. Among them, MNL model is among the most widely used disaggregate models and is also widely used to research departure time decision problems $[67,68]$. This method is a logit model that can provide 3 or more options, and it is used to simply and clearly characterize decisions in the scheme [58]. Logit model can reveal the behavior rule of decision makers. The factors that affect the behavior of decision makers can be determined by analyzing the symbols, size and importance of the estimated parameters [69]. It can also estimate the willingness of decision makers to pay for goods, facilities and policies. Analysis of behavioral differences resulting from changes in factors, policy implementation, and increases or decreases in alternatives. In addition, the implementation effects of different measures and scenarios can be predicted in the early stage [10].

Thus, the Logit model can be used to analyze the travel behavior differences of holiday travelers after road pricing changes. Generally, travelers who plan to travel on holidays often need to make decisions about departure time. He or she may choose to departure before or during the holiday. Since the peak of congestion is highest on the first day of a holiday, in order to achieve the purpose of reducing the peak, the departure times were divided into the day before the holiday, the first day of the holiday and all other days of the holiday. The number of days in long holidays is relatively large, so the other days of long holidays were divided into the 2nd-4th days and the 5th-7th days of holidays, which represent the middle and the end of the holiday, respectively. Therefore, this paper adopts the MNL model to establish the departure time behavior decision model for travelers on short and long vacations respectively (the model framework is shown in Figure 1), and the effects of each influencing factor on the tourists' choice behavior for three-day and seven-day holidays were compared. 


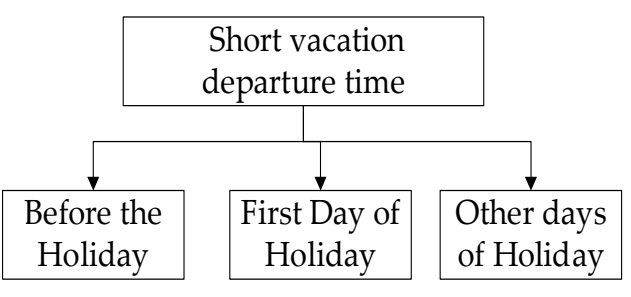

(a) Short vacation model

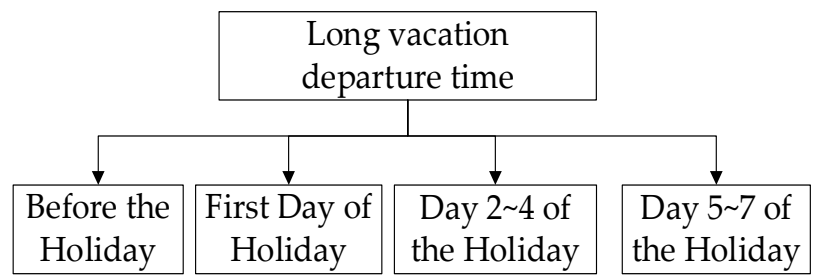

(b) Long vacation model

Figure 1. Multinomial logit (MNL) model framework for short holiday and long Holiday.

Multinomial logit model (MNL) is based on the theory of random utility, which assumes that individuals will choose the most effective scheme in the face of multiple independent options; that is, they will aim for "utility maximization". Generally, the utility function is linear and consists of fixed terms and random terms: a fixed term is an observable term; a random term is an unobservable term, which mainly includes non-observable travel-related attributes, non-observable traveler's socioeconomic attributes and measurement error $[30,55]$. The departure time choice behavior of holiday travelers can be described by the utility function. Different schemes have different utility for travelers, assuming that travelers choose a scheme that maximizes utility from a set of alternatives available to them. The utility function of choosing alternative in the MNL model is as follows:

$$
\begin{gathered}
U_{\text {in }}=V_{\text {in }}+\varepsilon_{\text {in }},\left(i \in A_{n}\right), \\
V_{\text {in }}=A S C_{i}+\sum_{k=1}^{K} \theta_{k} X_{i n k},\left(i \in A_{n}\right),
\end{gathered}
$$

where $U_{\text {in }}$ is the utility of the traveler $n$ who selects scheme $i ; V_{i n}$ is a fixed term in the utility function of the explanatory variables associated with traveler $n$ and alternative $i ; \varepsilon_{i n}$ is a random component in the utility function, which captures all other factors unobserved by the researcher; $A_{n}$ is the available choice set for individual $n ; A S C_{i}$ is an Alternative Specific Constant that captures systematic but unexplained variability in the data; $\theta_{k}$ the unknown parameter to be estimated; $X_{i n k}$ is the $k$ th variable of alternative $i$ for traveler $n ; K$ is the number of characteristic variables.

It is assumed that the utility function follows the Gumbel distribution, and the probability of traveler choosing alternative in the MNL model is as follows:

$$
P_{i n}=\frac{e^{V_{i n}}}{\sum_{j \in A_{n}} e^{V_{j n}}}=\frac{1}{\sum_{j \in A_{n}} e^{V_{j n}-V_{i n}}},\left(i \in A_{n}\right)
$$

\subsection{Investigation Methods}

In order to investigate and reflect the preferences of holiday travelers in actual travel situations, we must first obtain real holiday travel data. At the same time, it is necessary to determine the stated preferences of travelers in different policy situations to obtain travel behavior in such scenarios. Therefore, the survey was a combination of display preference (Revealed Preference, RP) and declarative preference (Stated Preference, SP) methods, and a simple random sampling technique was used to identify survey respondents [70].

The questionnaire is divided into three parts.

Part 1 is designed to collect the demographic characteristics of travelers, including gender, age, income, number of family members, etc. 
Part 2 is a survey of the travel characteristics of tourists on holidays. It requests information about tourists' recent short and long vacations, including trip duration, number of tourists (tourist group) and relationships to them, the number of visits, travel motivation, travel distance, departure time, etc.

Part 3 is intended to analyze the behavioral intention that drives decisions on departure times. Four characteristic variables-namely, pre-holiday charges, charges on the first day of the holiday, charges on other days of the holiday and the predicted congestion time on the first day of the holiday-were selected to characterize travel behaviors in response to road toll changes and pre-travel congestion information on the first day.

In addition, an orthogonal experimental design was developed to analyze the effects of different toll scenarios. With the aim of diverting passenger flow, the principle of the pricing scheme is that the charge on the first day of a holiday is greater than or equal to that on the other days of the holiday. Finally, 7 pricing scenarios were formed, named $S_{1}-S_{7}$, and their specific meanings are shown in Table 1. Scenario $S_{0}$ refers to the free passage of cars with seven seats or less on the expressway on legal holidays and the implementation of tolls on the expressway outside of holidays (current situation).

Table 1. Combination of charges for different departure times.

\begin{tabular}{cccccccc}
\hline & \multicolumn{3}{c}{ Three-Day Short Vacation } & \multicolumn{4}{c}{ Seven-Day Long Vacation } \\
\cline { 2 - 8 } Scene & $\begin{array}{c}\text { 1-2 Days } \\
\text { before } \\
\text { Holiday }\end{array}$ & $\begin{array}{c}\text { First Day } \\
\text { of } \\
\text { Holiday }\end{array}$ & $\begin{array}{c}\text { Other } \\
\text { Days of } \\
\text { Holiday }\end{array}$ & $\begin{array}{c}\text { 1-2 Days } \\
\text { before } \\
\text { Holiday }\end{array}$ & $\begin{array}{c}\text { First Day } \\
\text { of } \\
\text { Holiday }\end{array}$ & $\begin{array}{c}\text { 2-4 Days } \\
\text { of } \\
\text { Holiday }\end{array}$ & $\begin{array}{c}\text { 5-7 Days } \\
\text { of } \\
\text { Holiday }\end{array}$ \\
\hline $\mathrm{S}_{0}$ & Full price & Free & Free & Full price & Free & Free & Free \\
$\mathrm{S}_{1}$ & Full price & Full price & Full price & Full price & Full price & Full price & Full price \\
$\mathrm{S}_{2}$ & Full price & Full price & Free & Full price & Full price & Free & Free \\
$\mathrm{S}_{3}$ & Full price & Half price & Half price & Full price & Half price & Half price & Free \\
$\mathrm{S}_{4}$ & Half price & Half price & Free & Half price & Half price & Free & Free \\
$\mathrm{S}_{5}$ & Half price & Full price & Half price & Half price & Full price & Half price & Free \\
$\mathrm{S}_{6}$ & Free & Full price & Free & Free & Full price & Free & Full price \\
$\mathrm{S}_{7}$ & Free & Free & Free & Free & Free & Free & Free \\
\hline
\end{tabular}

Note: the color in the table indicates that the charge is different from the current charge, and the redder the color indicates that the higher the charge, the less the discount.

\section{Data and Modeling}

\subsection{Sample Description}

This study was carried out by using a network questionnaire survey in December 2019, assisted by the domestic Internet survey platform "SO JUMP", and random travelers with holiday car travel experience were recruited as the respondents. The sample covers 27 administrative regions of China (34 in total) by statistical analysis of Internet Protocol (IP) address of respondents. A total of 544 questionnaires were obtained. After excluding surveys with obvious contradictions and incomplete answers, 460 valid questionnaires were retained, accounting for $84.6 \%$ of the total number of received questionnaires.

The basic information on the demographic and socioeconomic attributes of the respondents is shown in Table 2, including gender, age, personal monthly income, education level, occupation, family structure and disposable tourism time. The statistics of personal socioeconomic attributes from valid questionnaires showed that there were slightly more males than females, with males accounting for $52.04 \%$. Age was mainly concentrated in the young and middle ages of $24-44$ years old, accounting for $76.84 \%$. The highest level of education was a bachelor's degree/junior college degree, accounting for $52.69 \%$. The proportion of employees, administrators of institutions, students and teachers was $88.09 \%$, with middle and high incomes ranging from 5000 to 12,000 , accounting for $61.99 \%$. The size and structure of families were mainly 3-member nuclear families, accounting for $42.58 \%$. 
Table 2. Socio-demographic characteristics of the sample.

\begin{tabular}{|c|c|c|c|c|c|}
\hline Variable & Description & Percentage (\%) & Variable & Description & Percentage (\%) \\
\hline \multirow{2}{*}{ Gender } & Male & 52.04 & \multirow{5}{*}{$\begin{array}{l}\text { Monthly } \\
\text { income } \\
\text { (RMB) }\end{array}$} & $(0,3000]$ & 14.03 \\
\hline & Female & 47.96 & & $(3000,5000]$ & 12.23 \\
\hline \multirow{5}{*}{$\begin{array}{l}\text { Age } \\
\text { (years) }\end{array}$} & $18-23$ & 9.62 & & $(5000,8000]$ & 29.53 \\
\hline & $24-34$ & 54.16 & & $(8000,12,000]$ & 32.46 \\
\hline & $35-44$ & 22.68 & & 12,000 & 11.75 \\
\hline & $45-54$ & 9.46 & \multirow{2}{*}{$\begin{array}{l}\text { Family } \\
\text { size and } \\
\text { structure }\end{array}$} & $\begin{array}{c}1 \text { person } \\
\text { (living alone/single, etc.) }\end{array}$ & 11.25 \\
\hline & $55-65$ & 4.08 & & $\begin{array}{c}2 \text { persons (married } \\
\text { without children, etc.) } \\
3 \text { persons (living with }\end{array}$ & 13.87 \\
\hline \multirow{3}{*}{$\begin{array}{l}\text { Education } \\
\text { level }\end{array}$} & High school or below & 7.01 & & $\begin{array}{l}\text { parents/married with } \\
1 \text { child, etc.) }\end{array}$ & 42.58 \\
\hline & Junior college/Bachelor's degree & 52.69 & \multirow{8}{*}{ Occupation } & $\begin{array}{c}4 \text { or more } \\
\text { (multi-child/living with } \\
\text { elderly etc.) }\end{array}$ & 32.3 \\
\hline & Master's degree & 27.41 & & Staff & 23.98 \\
\hline \multirow{6}{*}{$\begin{array}{l}\text { Disposable } \\
\text { tourism } \\
\text { time }^{1}\end{array}$} & Doctorate degree & 12.89 & & Worker & 35.89 \\
\hline & Single day off and statutory holidays & 9.62 & & Teachers & 10.77 \\
\hline & Two days off and statutory holidays & 30.35 & & Student & 17.45 \\
\hline & $\begin{array}{l}\text { Two days off, statutory holidays, and } \\
\text { paid annual leave }\end{array}$ & 27.24 & & Retired/Unemployed & 4.08 \\
\hline & $\begin{array}{l}\text { Two days off, statutory holidays, and } \\
\text { summer/winter vacation }\end{array}$ & 22.51 & & Freelance & 5.71 \\
\hline & Lots of free time & 10.28 & & Other & 2.12 \\
\hline
\end{tabular}

\subsection{Data Analysis}

The RP and SP data were divided into short vacations and long vacations, respectively. Through our analysis, we found that traffic characteristics differ between long and short holidays.

First, most travelers have experienced different degrees of traffic jams on holiday trips. The proportion of tourists who encountered traffic jams during short holidays and long holidays is $78.6 \%$ and $81.6 \%$, respectively, among which $25.2 \%$ and $30.7 \%$ lasted more than $30 \mathrm{~min}$, respectively.

Second, there are differences in travel characteristics between long and short vacations (RP data).

(1) Under the current condition of free passage on expressways during holidays, the proportion of departures on the first day of the holiday, is significantly higher than that on other days. First-day departures on short and long holidays account for $62.3 \%$ and $49.6 \%$, respectively. The proportion of departures occurring before and on other days of long vacations is more than that of short vacations. The proportion of departure times near the end of holidays is very low: for example, $4.1 \%$ on the third day of a short holiday and $2.5 \%$ on the fifth to seventh days of a long holiday. It can be seen that limited holidays and travelers' intentions to make full use of holidays tend to cause travelers to choose departure times in the first half of their holidays.

(2) The proportion of urban and suburban travel is higher during short holidays than that during long holidays, and the travel distance is mostly concentrated within $300 \mathrm{~km}$. However, the proportion of cross-city travel during long vacations is considerably higher than that during short vacations, and the travel distance is more than $200 \mathrm{~km}$. It can be seen that the longer the holiday time, the higher the proportion of cross-city travel, and the farther the travel distance.

(3) There are differences in travel duration of different holidays, the proportion of one-day trips is as high as $42.8 \%$ on short holidays. The trip duration of long vacations is more uniform than that of short vacations; trips that last 4 days or more account for $70.1 \%$ of long trips, among which 4-day trips are the most frequent. Since the length of holidays directly affects the length of travel, adjusting the length of holidays can directly affect the trip duration.

(4) On the whole, the most common motivations are leisure and relaxation, visits to scenic spots and seeing family members. In particular, the purpose of leisure and relaxation is as frequent as $51.2 \%$ for short vacations, while the purposes of sightseeing and visiting relatives and friends are significantly more common for long vacations than that for short vacations. Travelers on short 
vacations are likely to be more eager to relax, while travelers on long vacations have more time to savor scenic spots and visit friends and relatives.

Moreover, RP data show that departure time distributions vary between different but related factors, as shown in Figures 2-5.

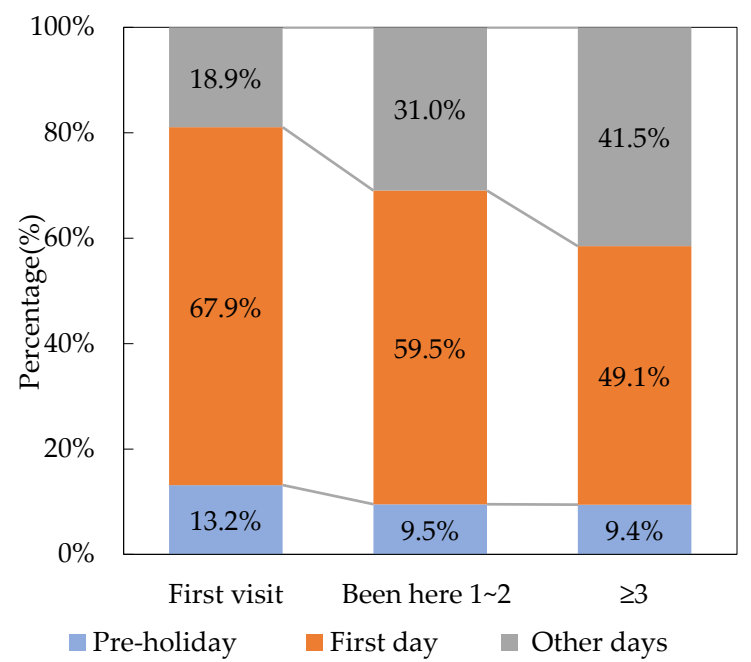

(a) Short vacation

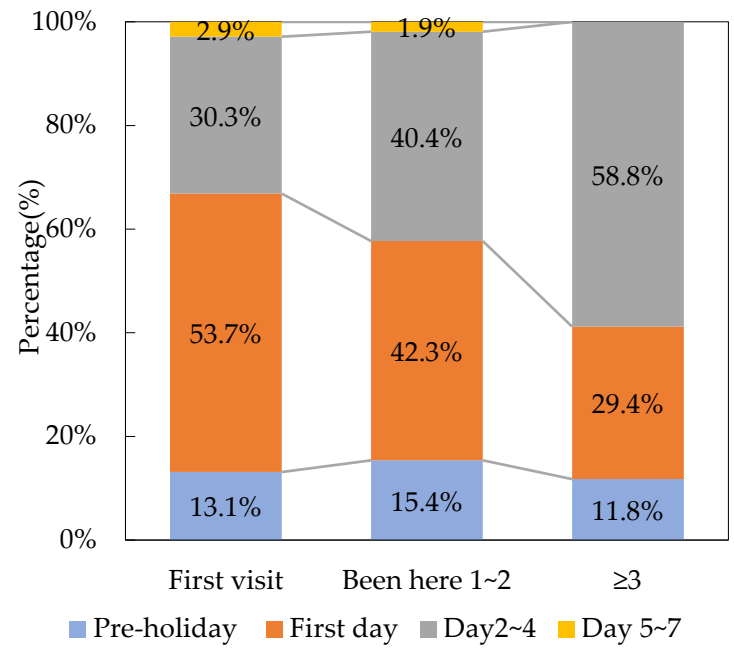

(b) Long vacation

Figure 2. Distribution of departure times under different number of visits.

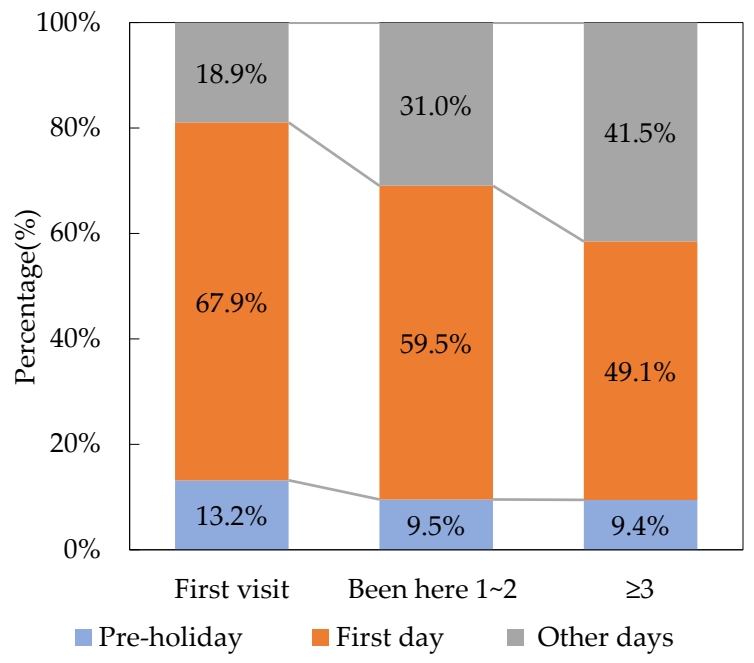

(a) Short vacation

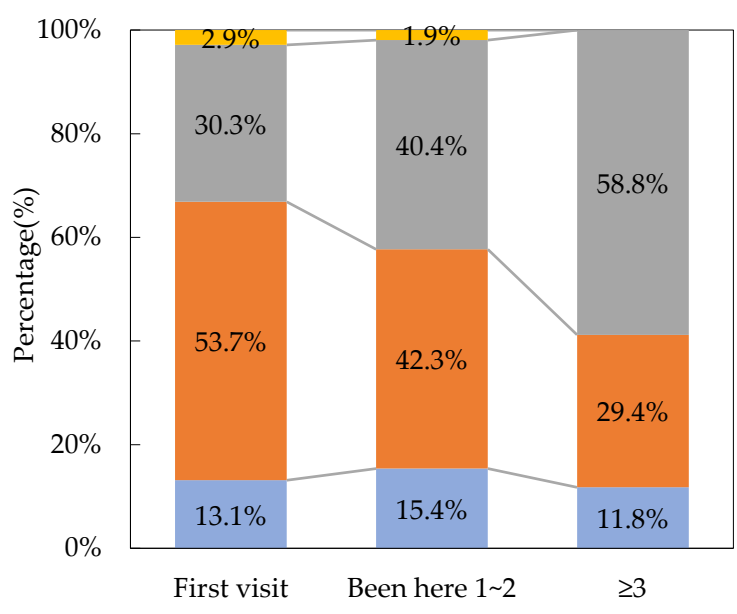

$\square$ Pre-holiday $\square$ First day $\square$ Day2 4 $\square$ Day 5 7

(b) Long vacation

Figure 3. Distribution of departure times for short and long holiday under different travel ranges. 


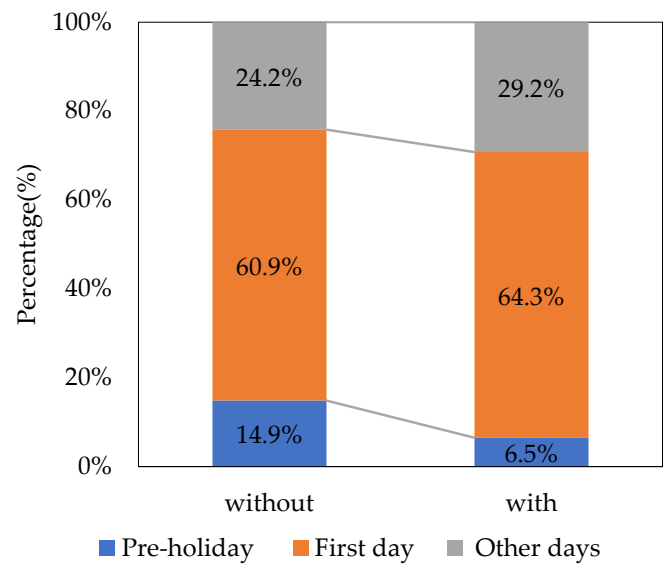

(a) Short vacation

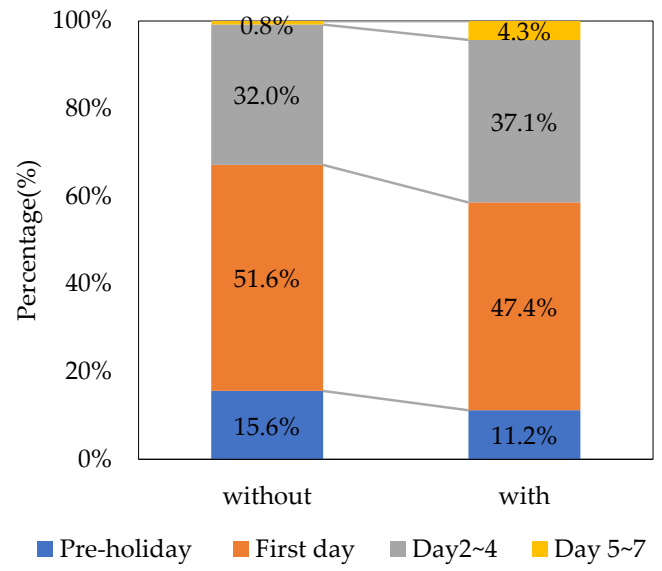

(b) Long vacation

Figure 4. Distribution of departure times under with/without children together.

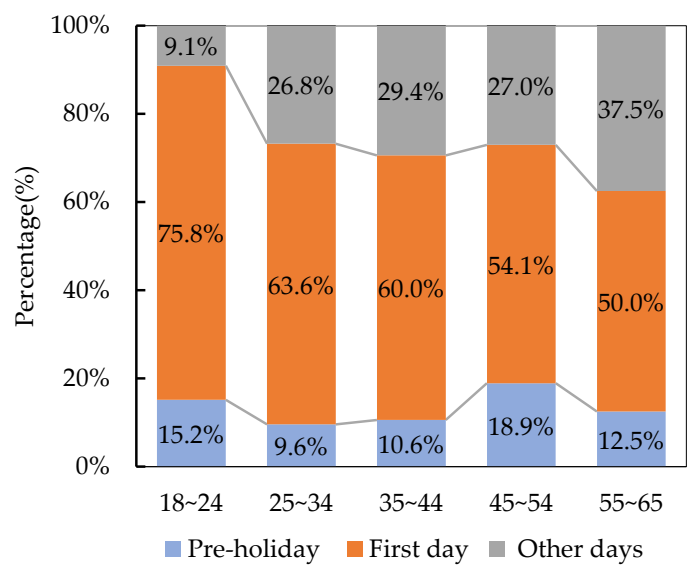

(a) Short vacation

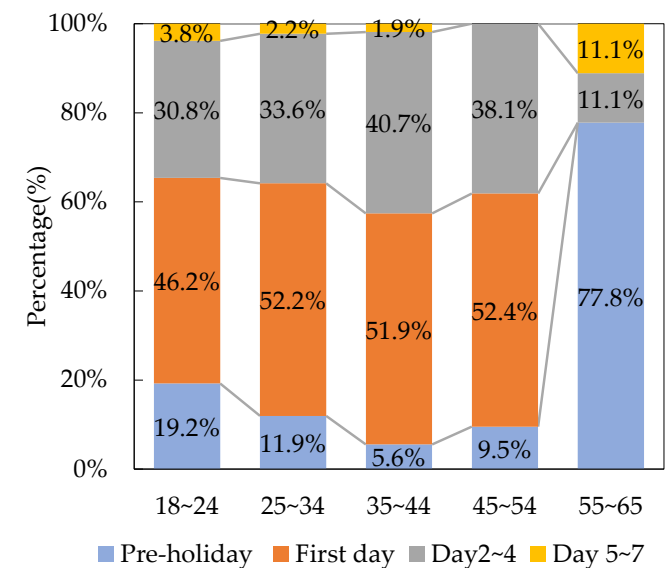

(b) Long vacation

Figure 5. Distribution of departure times for short and long holiday under different ages.

(1) Figure 2 shows that the departure times of travelers differ depending on the number of previous trips. Among respondents with different travel experience, first-time travelers have the highest likelihood of departing on the first day of a holiday, and it is higher for a short vacation than for a long vacation, with proportions of $67.9 \%$ and $53.7 \%$, respectively. As the number of previous visits to scenic spots increases, the proportion of travel on other days of holidays gradually increases, the proportion of travel on the first day gradually decreases, and the change is greater for long holidays than for short holidays. Thus, travelers with more travel experience are often willing to stagger their trip to avoid the congestion peak on the first day and rationally choose their departure time. On the other hand, first-time travelers cannot wait to see the sights for the first time, so they most often choose to start their trip on the first day of the holiday to make the most of it.

(2) Figure 3 shows the distribution of departure times for different travel ranges. Overall, departure on the first day of short holidays is the most common (more than 50 percent). As the travel range expands, the proportion of first-day departures increases, the period of short vacations grows slowly, and the period of long vacations grows more rapidly. For long vacations, first-day departures for suburban and cross-city trips increase by $27 \%$ and $27.9 \%$, respectively, compared with trips in the city. However, the proportion of urban and suburban 
trips on other days is relatively high, and the proportion of urban trips during long vacations is mostly concentrated on other days of holidays. The proportion of cross-city travelers choosing to leave before the holiday is as high as $75 \%$, which is much higher than that of urban and suburban travelers.

(3) The proportion of the travel group with children on short and long holidays was $41.7 \%$ and $47.5 \%$, respectively. Figure 4 shows that the probability of departure before the holiday for tourists without children in short holidays is $14.9 \%$, which is obviously higher than that of the group with children, while the gap between long holidays is not obvious. Both groups with and without children departure time on the first day of the holiday in a higher proportion. In short holidays, the group with children was slightly higher than the group without children, while the long holiday is the opposite. The proportion of other days of the holiday is more with children than without children.

(4) Figure 5 shows the departure times of travelers of different ages. For short vacations, the rate of departure on the first day decreases as age increases, the proportion of departures on other days of the holiday continuously increases, and the proportion of departures before holidays is evenly distributed. For long vacations, the first-day departure rate is not significantly different for travelers under the age of 54 . The percentage of travelers over the age of 55 who choose to depart on the first day drops sharply, while the percentage of travelers who leave before the holiday jumps to $77.8 \%$. This may be due to the fact that travelers in this age group are mostly retired people with more free time and are generally willing to avoid peak travel days. On the whole, 25-54-year-olds make up a relatively high proportion of holiday travelers. Most of the travelers in this age group are of a prime working age, and the limited holiday time limits their travel departure time.

Finally, the departure times are compared between toll-free (RP data) and road toll strategy (SP data) for short holidays and long holidays. As can be seen in Figure 6, with the abolition of the free highway policy (SP data), the proportion of first-day departures decreases significantly, from $62.3 \%$ to $50.9 \%$, for a short holiday, and it decreases from $49.6 \%$ to $38.7 \%$ for a long holiday. However, the proportion of pre-holiday departures increases significantly, while the proportion of departures during the rest of the holiday slightly decreases. It can be seen from the comparison results that when the charging policy is adjusted from the toll-free policy to a toll charging strategy, the proportion of different departure times changes considerably, and the frequency of first-day departures changes slightly more for short vacations than that for long holidays.

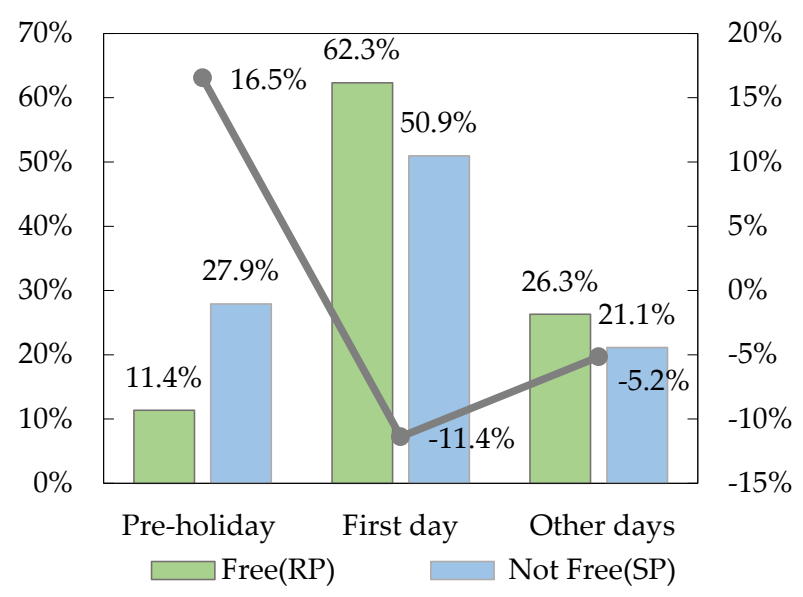

(a) Short vacation

Figure 6. Cont. 


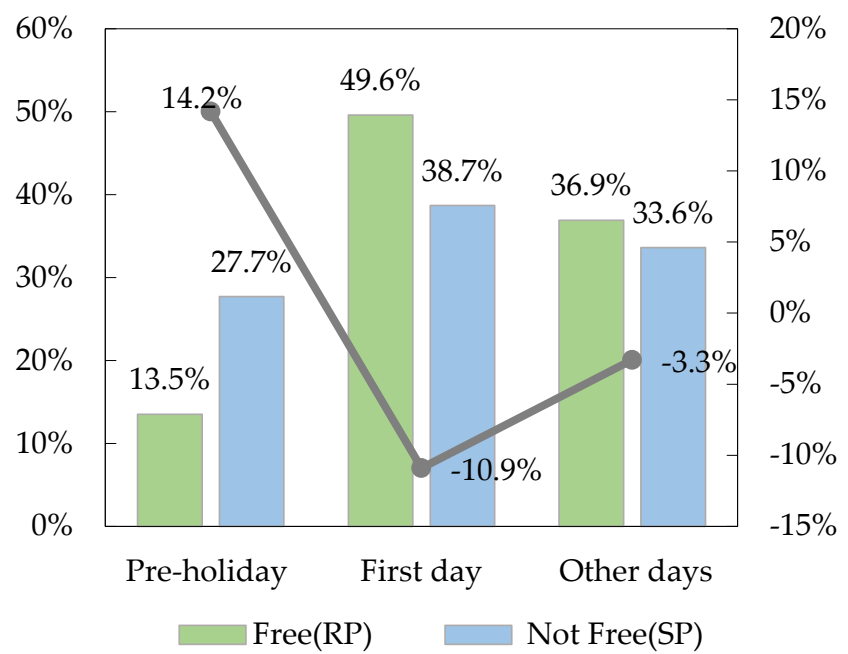

(b) Long vacation

Figure 6. Distribution of departure times under free and non-free policies.

\subsection{Model Specification}

Cross-contingency table and correlation analyses were carried out for the survey data, and the variables were screened. Statistically speaking, when $r \geq 0.6$, the data are related, and when $r \geq 0.8$, the data are highly correlated [69]. Therefore, variables with a correlation of more than 0.8 were eliminated, and the adjusted survey data were reintegrated. Finally, four variables, namely, socioeconomic characteristics, tour characteristics, travel characteristics and the external environment, were extracted as the variables of short and long holiday models. The specific parameter settings are shown in Table 3.

Table 3. Explanatory variables and parameter settings of MNL.

\begin{tabular}{|c|c|c|c|c|c|}
\hline $\begin{array}{l}\text { Variable } \\
\text { Category }\end{array}$ & Variable & & Parameter & $\begin{array}{l}\text { Corresponding } \\
\text { Model }\end{array}$ & $\begin{array}{c}\text { Parameter Setting and } \\
\text { Definition }\end{array}$ \\
\hline \multirow{6}{*}{$\begin{array}{c}\text { Tour } \\
\text { characteristics }\end{array}$} & Tourist group & $X_{i n 1}$ & $\theta_{1}$ & Short/Long ${ }^{1}$ & $\begin{array}{c}\text { divided into } 1-7 \text { persons and } \\
\text { above, value is } 1-7 \text {, taking the } \\
\text { actual value }\end{array}$ \\
\hline & $\begin{array}{l}\text { Relationship with } \\
\text { tourists }\end{array}$ & $X_{i n 2}$ & $\theta_{2}$ & Short/Long & $\begin{array}{c}1=\text { family, } \\
\text { friends/colleagues/classmates; } \\
0=\text { alone and other }\end{array}$ \\
\hline & Tour duration time & $X_{\text {in3 }}$ & $\theta_{3}$ & Short/Long & $\begin{array}{c}\text { divided into } 1-7 \text { days and } \\
\text { above, taking the actual value }\end{array}$ \\
\hline & The number of visits & $X_{i n 4}$ & $\theta_{4}$ & Short/Long & $\begin{array}{c}1=3+\text { times } ; 0=\text { first-time and } \\
1-2 \text { times }\end{array}$ \\
\hline & $\begin{array}{l}\text { With/without children } \\
\text { together }\end{array}$ & $X_{i n 5}$ & $\theta_{5}$ & Short/Long & $1=$ without $; 0=$ with \\
\hline & $\begin{array}{l}\text { With/without old man } \\
\text { together }\end{array}$ & $X_{\text {in6 }}$ & $\theta_{6}$ & Short/Long & $1=$ without $; 0=$ with \\
\hline
\end{tabular}


Table 3. Cont.

\begin{tabular}{|c|c|c|c|c|c|}
\hline $\begin{array}{l}\text { Variable } \\
\text { Category }\end{array}$ & Variable & & Parameter & $\begin{array}{l}\text { Corresponding } \\
\text { Model }\end{array}$ & $\begin{array}{c}\text { Parameter Setting and } \\
\text { Definition }\end{array}$ \\
\hline \multirow{6}{*}{$\begin{array}{l}\text { Socioeconomic } \\
\text { characteristics }\end{array}$} & Occupation & $X_{i n 7}$ & $\theta_{7}$ & Short/Long & \multirow{9}{*}{$\begin{array}{c}1=\text { staff and worker; } \\
0=\text { teacher, student, } \\
\text { retired/unemployed, freelance } \\
1=>5000 ; 0=(0,5000] \\
1=18-44 ; 0=45-65 \\
1=\text { undergraduate and below; } \\
0=\text { graduate and above } \\
1=\text { single/two day off and } \\
\text { statutory holidays; } 0=\text { other } \\
1=\text { in the city and suburbs; } \\
0=\text { cross-city } \\
\text { divided into }(0,1],(1,2],(2,3], \\
(3,4],(4,5],(5,6], 6 \text { h and above, } \\
\text { value is } 1-7 \\
\text { divided into }(0,1],(1,2],(2,3], \\
(3,4],(4,5],(5,6],(6,7],(7,8], \\
>8 \mathrm{~h}, \text { value is } 1-9 \\
1=\text { first day of the holiday; } \\
0=\text { other }\end{array}$} \\
\hline & Monthly income & $X_{i n 8}$ & $\theta_{8}$ & Short/Long & \\
\hline & Age & $X_{i n 9}$ & $\theta_{9}$ & Short/Long & \\
\hline & Education level & $X_{i n 10}$ & $\theta_{10}$ & Long & \\
\hline & Disposable tourism time & $X_{i n 11}$ & $\theta_{11}$ & Long & \\
\hline & Travel range & $X_{i n 12}$ & $\theta_{12}$ & Short/Long & \\
\hline \multirow{4}{*}{$\begin{array}{c}\text { Travel } \\
\text { characteristics }\end{array}$} & \multirow[t]{3}{*}{ Travel time } & $X_{\text {in13 }}$ & $\theta_{13}$ & Short & \\
\hline & & & & Long & \\
\hline & & $X_{\text {in14 }}$ & $\theta_{14}$ & Short/Long & \\
\hline & Travel experience ${ }^{2}$ & $X_{\text {in15 }}$ & $\theta_{15}$ & Short & $\begin{array}{l}1=\text { other days of holidays; } \\
\quad 0=\text { other }\end{array}$ \\
\hline \multirow{6}{*}{$\begin{array}{l}\text { External } \\
\text { conditions }\end{array}$} & & $X_{\text {in16 }}$ & $\theta_{16}$ & Long & $\begin{array}{c}1=\text { day } 2-4 \text { of the holiday; } \\
0=\text { other } \\
1=\text { day } 5-7 \text { of the holiday; } \\
0=\text { other }\end{array}$ \\
\hline & Pre-holiday charges & $X_{\text {in17 }}$ & $\theta_{17}$ & Short/Long & $\begin{array}{l}\text { divided into full price, half } \\
\text { price, free, value is } 1-3\end{array}$ \\
\hline & $\begin{array}{c}\text { First day charges on } \\
\text { holidays }\end{array}$ & $X_{\text {in18 }}$ & $\theta_{18}$ & Short/Long & $\begin{array}{l}\text { divided into full price, half } \\
\text { price, free, value is } 1-3\end{array}$ \\
\hline & $\begin{array}{l}\text { Length of congestion on } \\
\text { the first day }\end{array}$ & $X_{i n 19}$ & $\theta_{19}$ & Short/Long & $\begin{array}{l}\text { divided into } 30-60,60-120 \\
120 \text { min or more, value is } 1-3\end{array}$ \\
\hline & \multirow[t]{2}{*}{$\begin{array}{l}\text { Charges for the rest of } \\
\text { the holiday }\end{array}$} & $X_{i n 20}$ & $\theta_{20}$ & Short & $\begin{array}{l}\text { divided into full price, half } \\
\text { price, free, value is } 1-3 \\
\text { charges for the } 2 \text { nd }-4 \text { th day of }\end{array}$ \\
\hline & & $X_{i n 21}$ & $\theta_{21}$ & Long & $\begin{array}{l}\text { holiday: full price, half price, } \\
\text { free, value is } 1-3 \\
\text { charges for the } 5 \text { th }-7 \text { th day of } \\
\text { holiday: full price, half price, } \\
\text { free, value is } 1-3\end{array}$ \\
\hline
\end{tabular}

${ }^{1}$ Short/Long represents the short vacation model and the long vacation model. ${ }^{2}$ Travel experience represents departure time of last holiday tour.

According to the characteristic variables of the MNL model, the utility functions of the short and long holiday models were established, as shown in formulas (4)-(6) and (7)-(10), respectively.

(1) The utility functions of each selected limb of the short holiday model are as follows:

(1) Utility function for departure before a holiday:

$$
V_{1 n}=\theta_{2} X_{1 n 2}+\theta_{3} X_{1 n 3}+\theta_{13} X_{1 n 13}+\theta_{17} X_{1 n 17}
$$

(2) Utility function for departure on the first day of a holiday:

$$
V_{2 n}=A S C_{1}+\theta_{1} X_{2 n 1}+\theta_{4} X_{2 n 4}+\theta_{8} X_{2 n 8}+\theta_{9} X_{2 n 9}+\theta_{14} X_{2 n 14}+\theta_{18} X_{2 n 18}+\theta_{19} X_{2 n 19}
$$

(3) Utility function for departure on other days of the holiday:

$$
V_{3 n}=A S C_{2}+\theta_{5} X_{3 n 5}+\theta_{6} X_{3 n 6}+\theta_{7} X_{3 n 7}+\theta_{12} X_{3 n 12}+\theta_{15} X_{3 n 15}+\theta_{20} X_{3 n 20}
$$


(2) The utility functions of each selected limb of the long holiday model are as follows:

(1) Utility function for departure before a holiday:

$$
V_{1 n}=\theta_{2} X_{1 n 2}+\theta_{3} X_{1 n 3}+\theta_{10} X_{1 n 10}+\theta_{13} X_{1 n 13}+\theta_{17} X_{1 n 17}
$$

(2) Utility function for departure on the first day of a holiday:

$$
V_{2 n}=A S C_{1}+\theta_{1} X_{2 n 1}+\theta_{4} X_{2 n 4}+\theta_{8} X_{2 n 8}+\theta_{11} X_{2 n 11}+\theta_{13} X_{2 n 13}+\theta_{14} X_{2 n 14}+\theta_{18} X_{2 n 18}+\theta_{19} X_{2 n 19}
$$

(3) Utility function for departure on the 2nd-4th day of the holiday:

$$
V_{3 n}=A S C_{2}+\theta_{5} X_{3 n 5}+\theta_{7} X_{3 n 7}+\theta_{9} X_{3 n 9}+\theta_{12} X_{3 n 12}+\theta_{15} X_{3 n 15}+\theta_{20} X_{3 n 20},
$$

(4) Utility function for departure on the 5th-7th day of the holiday:

$$
V_{4 n}=A S C_{3}+\theta_{6} X_{4 n 6}+\theta_{16} X_{4 n 16}+\theta_{21} X_{4 n 21}
$$

\section{Results and Discussion}

\subsection{Estimation Results of MNL Model}

In this study, the short holiday and long holiday models were calibrated. The specific parameter estimation results and related test values are shown in Table 4. Usually, when the goodness of fit reaches $0.2-0.4$, the accuracy of the model is considered to be high [55]. According to the calibration results of the model, the goodness of fit of the short and long vacation models are 0.221 and 0.254 ,

\begin{tabular}{|c|c|c|c|c|c|c|c|c|}
\hline & Variable & Parameter & \multicolumn{3}{|c|}{ Short Vacation Model } & \multicolumn{3}{|c|}{ Long Vacation Model } \\
\hline \multirow{6}{*}{$\begin{array}{c}\text { Tour } \\
\text { characteristics }\end{array}$} & Inherent dummy & $\mathrm{ASC}_{1}$ & 2.1 & 0.302 & $6.95^{* * *}$ & 1.68 & 0.483 & $2.40^{* *}$ \\
\hline & Inherent dummy (Long) & $\mathrm{ASC}_{3}$ & - & - & - & -1.65 & 0.484 & $-3.80 * * *$ \\
\hline & Tourist group & $\theta_{1}$ & -0.0924 & 0.0302 & $-3.07 * * *$ & -0.0868 & 0.0446 & $-1.94 * *$ \\
\hline & The number of visits & $\theta_{4}$ & -0.168 & 0.0911 & $-1.84^{*}$ & -0.75 & 0.249 & $-3.02^{* * *}$ \\
\hline & $\begin{array}{l}\text { With/without children } \\
\text { together }\end{array}$ & $\theta_{5}$ & -0.382 & 0.112 & $-3.4^{* * *}$ & 0.142 & 0.111 & 1.28 \\
\hline & $\begin{array}{l}\text { With/without old man } \\
\text { together }\end{array}$ & $\theta_{6}$ & 0.649 & 0.134 & $4.84^{* * *}$ & 0.561 & 0.248 & $2.26 * *$ \\
\hline \multirow{3}{*}{$\begin{array}{l}\text { Socioeconomic } \\
\text { characteristics }\end{array}$} & Disposable tourism time & $\theta_{11}$ & - & - & - & 0.404 & 0.146 & $2.76^{* * *}$ \\
\hline & Travel range & $\theta_{12}$ & 0.377 & 0.106 & $3.57 * * *$ & -0.519 & 0.144 & $-3.59 * * *$ \\
\hline & Travel time & $\theta_{13}$ & 0.252 & 0.034 & $7.4^{* * *}$ & -0.0351 & 0.0267 & 1.31 \\
\hline \multirow{3}{*}{$\begin{array}{c}\text { Travel } \\
\text { characteristics }\end{array}$} & $\begin{array}{l}\text { Travel experience1: } \\
\text { first day }\end{array}$ & $\theta_{14}$ & 1.15 & 0.117 & $9.76^{* * *}$ & 0.862 & 0.167 & $5.16^{* * *}$ \\
\hline & $\begin{array}{c}\text { Travel experience2: } \\
\text { other days (Short)/ } \\
\text { day 2-4 of the holiday } \\
\text { (Long) }\end{array}$ & $\theta_{15}$ & 1.55 & 0.127 & $12.25^{* * *}$ & 1.06 & 0.131 & $8.09^{* * *}$ \\
\hline & $\begin{array}{l}\text { Travel experience3: } \\
\text { day 5-7 of the holiday } \\
\text { (Long) }\end{array}$ & $\theta_{16}$ & - & - & - & 1.40 & 0.404 & $3.47^{* * *}$ \\
\hline
\end{tabular}
respectively, which indicates that the two models have high accuracies and can be used to describe the travel choice behavior of travelers during short and long holidays.

Table 4. Estimated parameters of short and long vacation MNL models. 
Table 4. Cont.

\begin{tabular}{|c|c|c|c|c|c|c|c|c|}
\hline & \multirow{2}{*}{ Variable } & \multirow{2}{*}{ Parameter } & \multicolumn{3}{|c|}{ Short Vacation Model } & \multicolumn{3}{|c|}{ Long Vacation Model } \\
\hline & & & Estimate & Std. Err. & $t$-Test & Estimate & Std. Err. & $t$-Test \\
\hline \multirow{6}{*}{$\begin{array}{l}\text { External } \\
\text { conditions }\end{array}$} & Pre-holiday charges & $\theta_{17}$ & 0.224 & 0.0583 & $3.85^{* * *}$ & 0.440 & 0.0762 & $5.78^{* * *}$ \\
\hline & $\begin{array}{c}\text { First day charges on } \\
\text { holidays }\end{array}$ & $\theta_{18}$ & 0.21 & 0.0596 & $3.52 * * *$ & 0.0964 & 0.09 & 1.07 \\
\hline & $\begin{array}{l}\text { Length of congestion on the } \\
\text { first day }\end{array}$ & $\theta_{19}$ & -0.298 & 0.0647 & $-4.61^{* * *}$ & -0.260 & 0.0948 & $-2.74^{* * *}$ \\
\hline & $\begin{array}{l}\text { Charges for day } 2-4 \text { of the } \\
\text { holiday }\end{array}$ & $\theta_{20}$ & 0.199 & 0.0689 & $2.89 * * *$ & 0.665 & 0.0796 & $8.35^{* * *}$ \\
\hline & $\begin{array}{c}\text { Charges for day } 5-7 \text { of the } \\
\text { holiday }\end{array}$ & \multirow[t]{2}{*}{$\theta_{21}$} & - & - & - & 0.370 & 0.124 & $2.97^{* * *}$ \\
\hline & Model statistics & & \multicolumn{3}{|c|}{$\begin{array}{l}L(0):-2837.716 \\
L(\hat{\theta}):-2267.730\end{array}$} & $\begin{array}{r}L \\
L \\
-2[L( \\
\rho^{2}\end{array}$ & $\begin{array}{l}\text { ): }-2367.7 \\
\hat{\theta}):-1765.6 \\
-L(\hat{\theta})]: 1 \\
0.254 \bar{\rho}^{2}: 0\end{array}$ & $\begin{array}{l}1 \\
5 \\
4.352 \\
44\end{array}$ \\
\hline
\end{tabular}

Note: ASC means alternative specific constant. "**", "**" and "***" respectively indicate that the significance index is less than $0.1,0.05$ and $0.01 .{ }^{1}$ Short/Long represents the short vacation model and the long vacation model.

1. Short vacation model

(1) Socioeconomic characteristics: (1) The influence coefficient of monthly income is negative and indicates that middle- and high-income travelers are less inclined to travel on the first day of a holiday. (2) The influence coefficient of age is positive and indicates that travelers aged 18-44 are more likely to travel on the first day of the holiday, while travelers aged 45-65 are more likely to travel before the holiday or on other days of the holiday to avoid peak travel and improve the travel experience.

(2) Trip characteristics: (1) The influence coefficient of trip duration is positive, which indicates that it is positively correlated with departure before a short holiday. The longer the travel time, the more inclined the traveler is to depart before the holiday. Because the length of a short vacation is limited, if the trip duration is fixed, travelers who need more travel time are more willing to depart before the holiday than to delay their departure and return later. (2) The negative influence coefficient of the tourist group shows that travelers become less inclined to travel on the first day of the holiday as the group size increases. This may be a response to traffic congestion on the first day of the holiday, which may lead to the loss of more time with more waiting when there are multiple travelers, and there is greater mutual influence and restriction. (3) The influence coefficient of the relationship between travelers is positive and indicates that a tourist who travels with family or friends tends to depart before the holiday. (4) The impact coefficient of the number of previous trips is negative, and it indicates that the greater the number of previous trips ( 3 times or more), the less inclined tourists are to set out on a peak travel day, which suggests that individuals who have traveled more in the past are more focused on the experience of travel. (5) The negative influence coefficient of whether children travel with respondents indicates that travelers without children generally do not choose to depart on other days of the holiday. Those without children have more freedom, so they are more likely to choose to travel before the holiday or on the first day of the holiday to make full use of the holiday time. (6) The influence coefficient of whether seniors accompany travelers is positive, which indicates that individuals lacking the accompaniment of older people tend to travel during holidays.

(3) Travel characteristics: (1) The influence coefficient of travel range is positive, indicating that the travelers in the city or suburb are more likely to travel on the second or third day of the holiday during the short vacation. (2) The impact coefficient of travel time is positive, indicating that travelers with longer travel time are more likely to travel before the holiday. (3) The influence coefficient of the last departure time is positive, indicating that the previous travel experience has a positive influence on the choice of departure time. 
(4) External conditions: (1) The influence coefficients of the three road toll factors are all positive, indicating that with the increase in the discount intensity of road toll, travelers on short vacations are more likely to choose a more favorable time to travel. (2) The influence coefficient of the predicted congestion duration on the first day is negative, indicating that travelers are less inclined to travel on the first day as the congestion duration increases.

2. Long vacation model

(1) Socioeconomic characteristics: (1) As in the short vacation model, the influence coefficient of monthly income is negative. (2) Age has a positive effect on departures on the 2nd-4th days in the long vacation model. Travelers aged 18-44 are more inclined to start their trips on the 2 nd-4th days of the holiday during a long vacation. The length of vacation is a major factor of this difference in choice. This may be because travelers in this group are mainly of school and work ages: family members have strict time constraints, and travel time is typically limited to holidays; thus, in order to fully enjoy holiday tourism during a short vacation, these travelers are more inclined to depart on the first day of the holiday. On the other hand, on long holidays, time is relatively abundant, so they may prefer to travel on the 2nd-4th days of the holiday. (3) Occupation has a positive impact coefficient (contrary to the short vacation model), and it indicates that administrators and workers are not inclined to depart on the 2nd-3rd day of short vacations and tend to travel on the second to the fourth day of long vacations. This is due to the fact that travelers with these occupations rest mainly on weekends and holidays, and they are more likely to choose to travel early or on the first day in order to fully enjoy the short vacation time. Long vacation breaks provide more time, making travelers in these occupations more likely to avoid peak travel.

(2) Trip characteristics: (1) As in the short vacation model, the influence coefficient of trip duration is also positive in the long vacation model. The influence coefficient of the short vacation model is larger than that of the long vacation model, which may be due to the reduced holiday time, the limited travel time and the greater willingness to start ahead of time. (2) The influence coefficient of the tourist group is negative, which is similar to the short holiday model. (3) The influence coefficient of the relationship with other tourists in the group is not significant, which is different from the positive correlation for short vacations, indicating that the relationship between travelers is not a decisive factor of departures before holidays. (4) The influence coefficient of the number of previous trips is negative, which is similar to the result in the short vacation model, but the influence degree in the long vacation model is greater than that in the short vacation model. This may be due to the fact that travelers can choose among more departure times during a long vacation period, while the possible departure times are relatively limited during a short vacation. (5) The influence coefficient of whether children accompany travelers is not significant in the long vacation model, which is different from the short vacation model. Time is abundant during a long vacation, and deciding whether to take children on trips has no notable influence on the choice of departure time. (6) The influence coefficient of whether seniors accompany travelers is positive (the same as the model of a short vacation) and indicates that travelers who are not accompanied by older people tend to depart on the 2nd-3rd day of a short vacation and the 5th-7th day of a long vacation.

(3) Travel characteristics: (1) Compared with the short vacation model, the travel range coefficient is negative. Travelers in the city or suburbs are more inclined to depart on other days of the holiday and do not tend to depart on the 2nd-4th days of a long holiday. This is likely because individuals who travel within or outside the city on a long holiday can choose from a wide range of departure times. (2) Travel time is not significant; this result is different from the short vacation model, indicating that the longer travel time of a long 
holiday does not necessarily lead to a choice to depart before the holiday, which may be due to the abundance of time on a long vacation. Travelers are more likely to adjust their departure times than the departure dates. The travel time of a long vacation is more likely to affect departure times than departure dates. (3) The influence coefficient of the departure time of previous trips is also positive, which indicates that prior travel experience positively affects the choice of departure time on a long vacation. Thus, travel experience is an important factor that affects the choice of departure time.

(4) External conditions: (1) The influence coefficients of the three road toll factors (before the holiday, the 2nd-4th day of the holiday and the 5th-7th day of the holiday) are all positive, indicating that as the discount of road tolls increases for the three departure times, travelers on long holidays are more likely to choose a time with a more favorable price. However, the effect of the first-day fee on the first-day departure is not significant, which is different from the short vacation model. This shows that a first-day fee as a single factor does not affect the first-day departure rate on a long vacation. Therefore, it may be necessary to design a combined pricing strategy to observe changes in behaviors. (2) The influence coefficient of the forecast of congestion on the first day is negative, but the coefficient is lower for the long vacation than the short vacation. On the one hand, this indicates that travelers become less inclined to travel on the first day as the congestion increases; on the other hand, it also reflects that the congestion forecast has a greater impact on a short vacation than on a long vacation, which may be due to the reduced vacation time of short holidays.

\subsection{Sensitivity Analysis of Variables}

In order to further quantitatively analyze the degree of influence of trip characteristics, travel characteristics and external policies on the travel decisions of tourists, the sensitivity of a given variable was analyzed while other factors in the model remained unchanged.

The point elasticity formula of the MNL model is as follows [70]:

$$
E_{X_{i n k}}^{P_{i n}}=\frac{X_{i n k}}{P_{\text {in }}} \cdot \frac{d P_{\text {in }}}{d X_{\text {ink }}}=\theta_{k} \cdot X_{i n k} \cdot\left[1-P_{i n}\right],
$$

Equation (11) can be used to calculate the relationships between the travel time, toll charge schedule (before/on the first day/on other days of the holiday) and the departure time probability, as well as the corresponding elastic values, in the short and long vacation models. The analysis of specific results is shown in Figures 7-14.

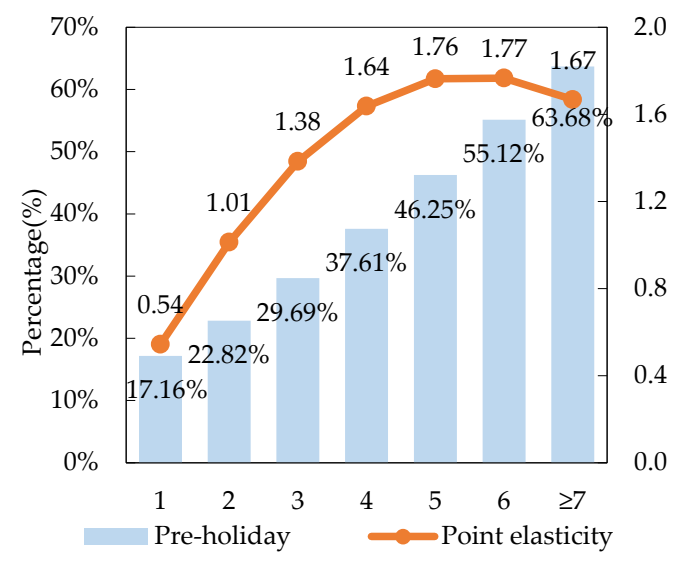

(a) Short vacation model

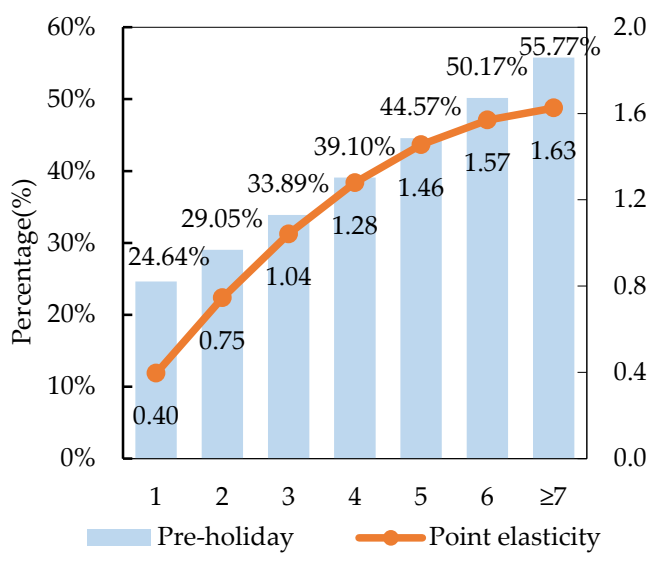

(b) Long vacation model

Figure 7. Probability and point elasticity of tour duration time. 


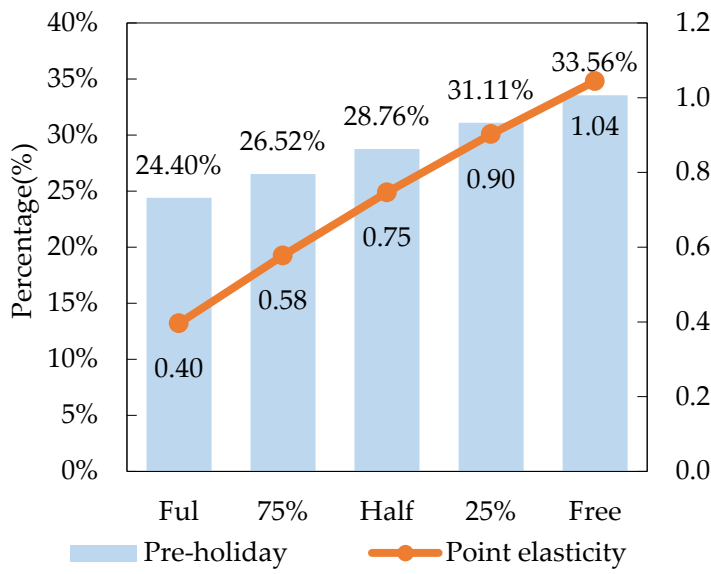

(a) Short vacation

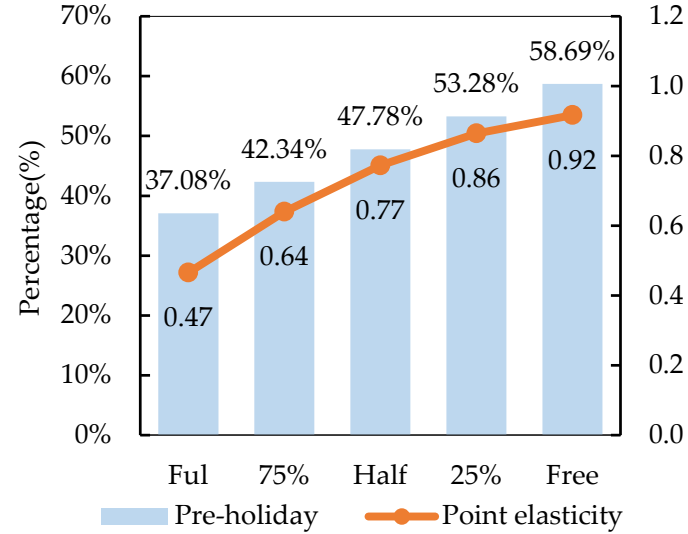

(b) Long vacation

Figure 8. Probability and point elasticity of pre-holiday pricing.

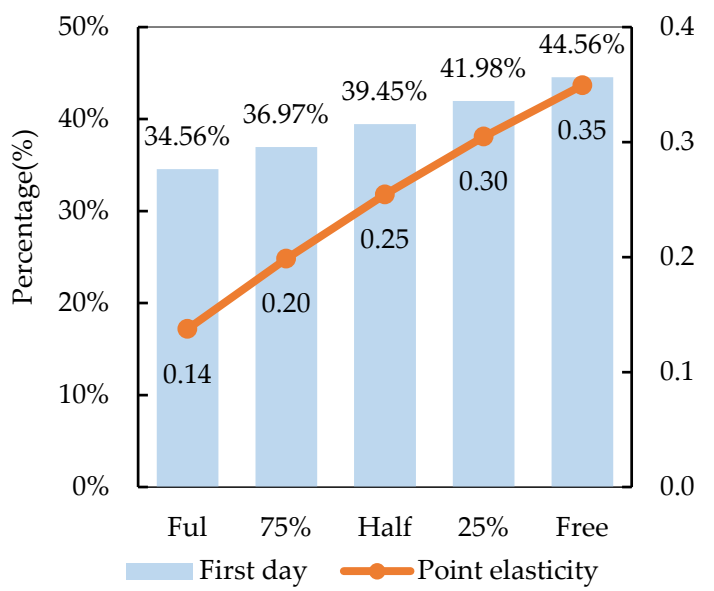

Figure 9. Probability and point elasticity of the first day pricing (short vacation).

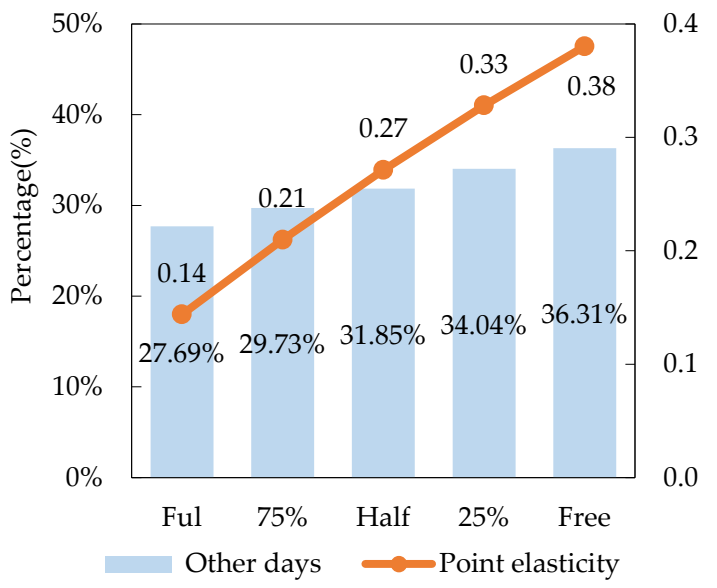

Figure 10. Probability and point elasticity of the other days pricing (short vacation). 


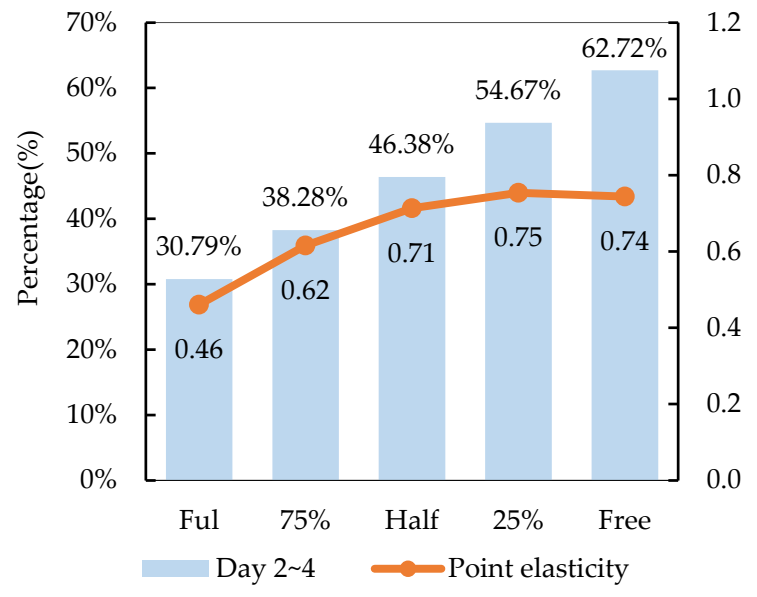

(a)Charges for day 2-4 of the holiday

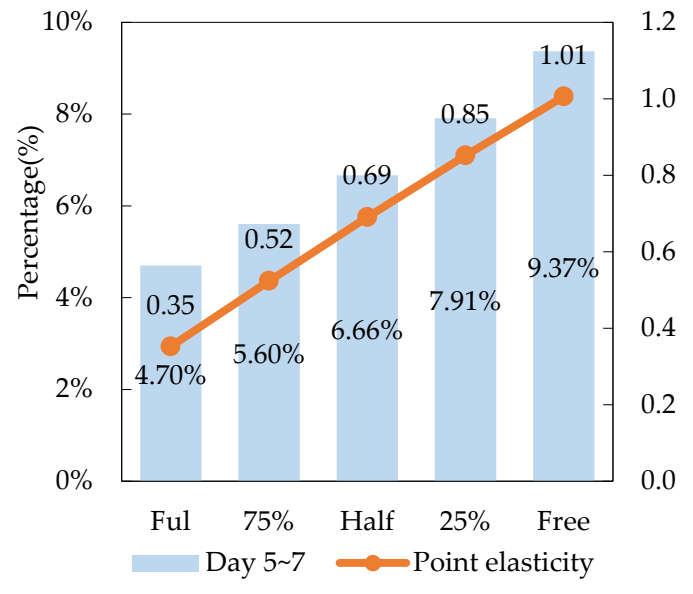

(b) Charges for day 5-7 of the holiday

Figure 11. Probability and point elasticity of the other days pricing (long vacation).

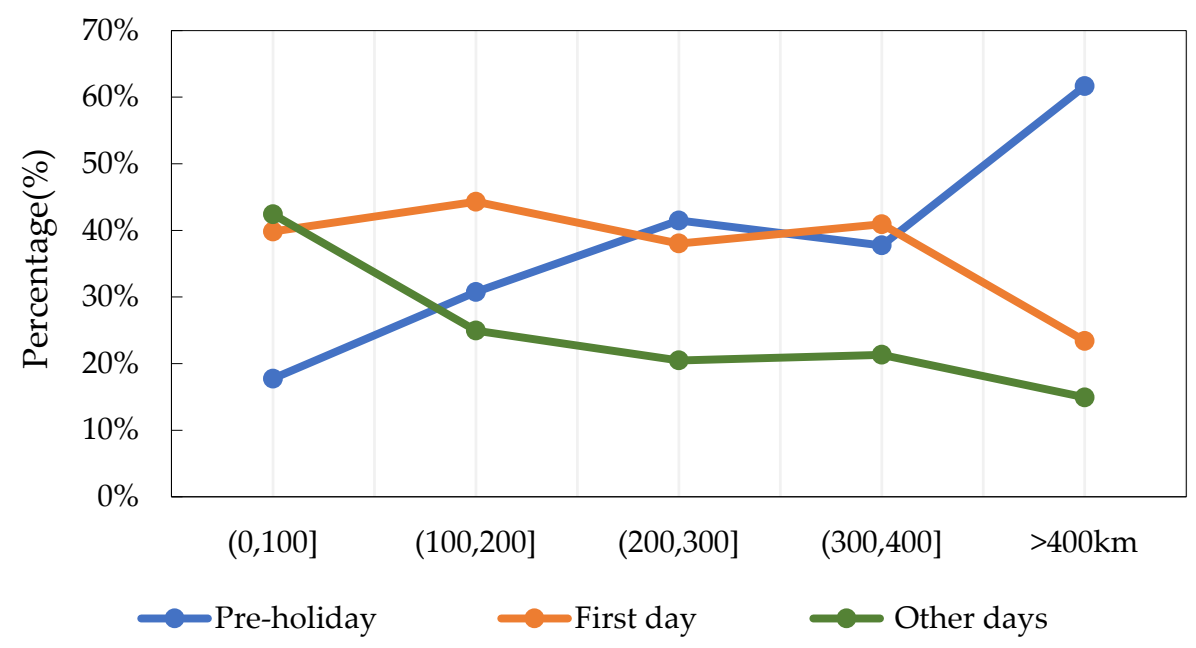

(a) Short vacation model

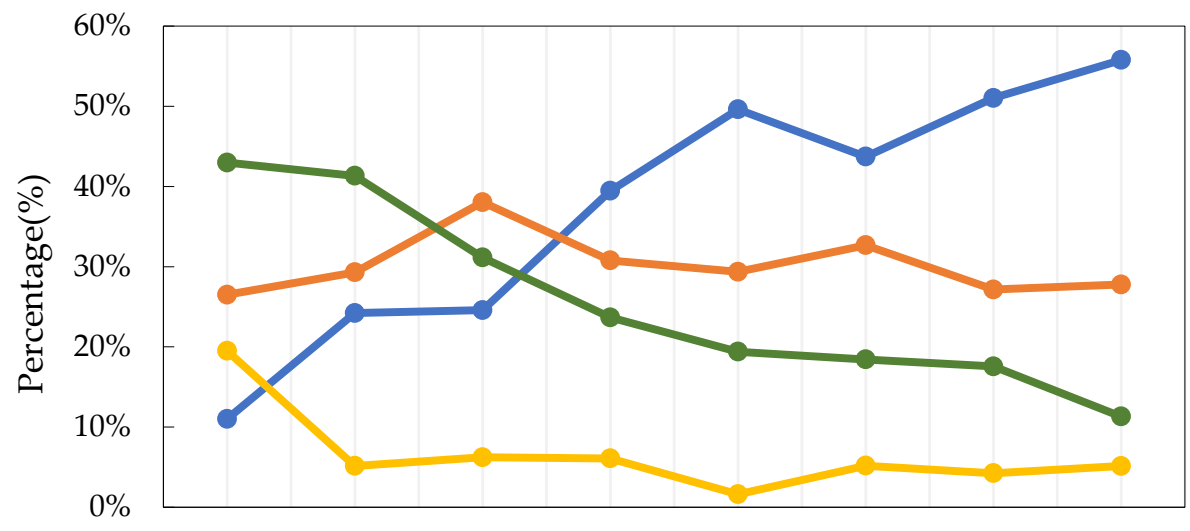

$(0,100](100,200](200,300](300,400](400,500](500,600](600,700]>700 \mathrm{~km}$

$\longrightarrow$ Pre-holiday $\longrightarrow$ First day $\longrightarrow$ Day2 4 Day 5 7

(b) Long vacation model

Figure 12. Probability variation of departure time at different distances. 


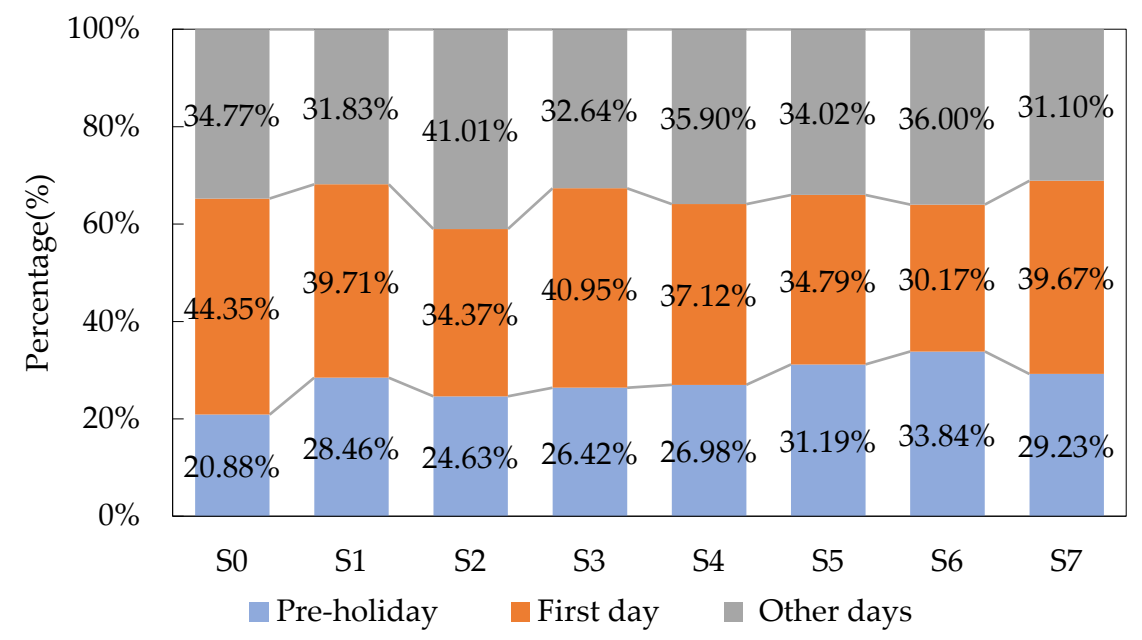

(a) Short vacation model.

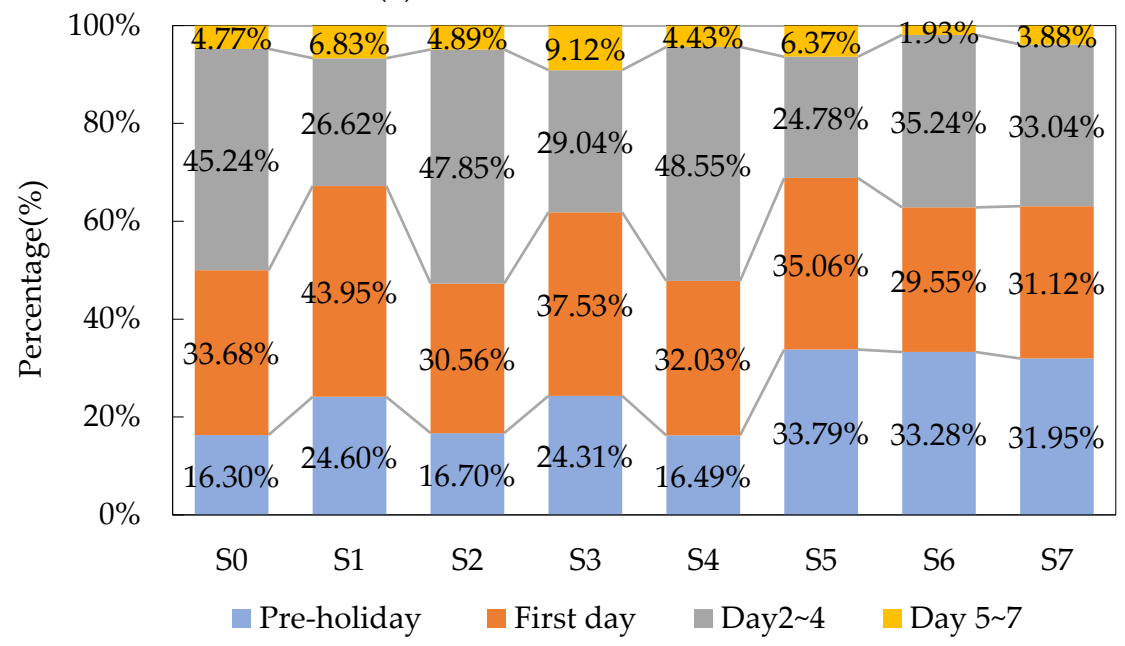

(b) Long vacation model.

Figure 13. Probability variation of departure time at different charging scenarios.

1. Sensitivity analysis of trip duration and departure probability before the holiday

Figure 7a,b show the trends of the point elasticity and the probability of departing before a holiday when the trip duration increases by one unit for short and long vacations. When the trip duration is $\geq 2$ days in the short vacation model and $\geq 4$ days in the long vacation model, the point elasticity value is greater than 1 , which means that the probability that travelers choose to depart before the holiday is elastic for the trip duration. This indicates that the trip duration is 2 days or more for a short vacation period and 4 days or more for a long vacation period, which will have a great impact on the probability of changing the traveler's departure before the holiday.

2. Sensitivity analysis of different road toll schemes and the traveler's probability of choosing different holiday departure times

(1) The trends of the point elasticity and probability that a traveler chooses to depart before a holiday is shown in Figure 8a,b for each pre-holiday charge level. The results show that the implementation of free pre-vacation travel on short holidays has a great impact on the probability that travelers choose to depart before a holiday. When the road is toll-free for 5 days or the holiday is extended for 5 days, travelers are more likely to travel before the holiday. The elasticity variation range of the long vacation model is weaker than that 
of the short vacation model, which indicates that the road toll before the holiday has relatively little influence on travelers on long vacations. This may be due to the sufficient time of a long vacation, and extending the toll-free days (or the length of the vacation) is not attractive enough to travelers.

(2) Because the application of a fee on the first day of the holiday has no significant effect on the long vacation model, the changes in the point elasticity and probability of first-day departures are presented only for the short vacation, as shown in Figure 9. It can be seen that the elastic value is between 0 and 1 , and it changes slightly as the travel discount increases, which indicates that the influence of the road charge on the probability that a traveler departs on the first day of a holiday is relatively weak. This reveals that a toll charge on the first day of a short holiday is not an important factor in the adjustment of departure times; thus, adjusting the rate on only the first day of a holiday does not have much of an effect on a traveler's choice to depart on the first day of the holiday. Given a choice between more time on a short holiday and first-day peak-travel fee concessions, people tend to choose to enjoy an extended short holiday.

(3) Figures 10 and 11 show the change in the point elasticity and probability of departure on other days of the holiday for each additional unit during a short holiday and a long holiday, respectively. In Figure 10, we can see that the elastic value for vacation travel charges on other days increases slowly with the increase in the discount value of fees, which indicates that the removal of road toll has a relatively weak influence on the probability of departure on other days of a short vacation. Figure 11 shows that the elasticity value of tolls on the 2nd-4th day and the 5th-7th day of a holiday gradually increases with the increase in the discount amount, indicating that the influence of a road discount on the departure time is stronger for a long vacation than for a short vacation.

\section{Analysis of departure time choice for different travel distances}

Figure 12a,b show the departure time probabilities for different distances for the short and long vacation models. In general, with the increase in travel distance, the probability of departure before vacation increases. (1) In the short vacation model, the probability of departure before vacation increases significantly when the distance is greater than $400 \mathrm{~km}$, while in the long vacation model, the probability of departure before vacation has the greatest increase when the distance is greater than $700 \mathrm{~km}$. (2) In the short holiday model, the probability of departure on the first day of the holiday is higher in all distance groups, especially for a travel distance of less than $400 \mathrm{~km}$, compared with the long holiday model. In the model of the long vacation, the probability of the first-day departure is relatively stable, and it is significantly higher for a distance of more than $200 \mathrm{~km}$ compared with other days of vacation. (3) During the short vacation, the probability of choosing other departure days is highest for distances of less than $100 \mathrm{~km}$, and as the travel distance increases, the probability of choosing to depart on other days of the holiday decreases gradually. The probability of departure on the 2 nd-4th days of the holiday is relatively high for distances of less than $200 \mathrm{~km}$ during a long vacation. The overall proportion of departures on the 5th-7th days of a holiday is lower. This also suggests that travelers tend to start their holiday travel earlier rather than later. Furthermore, for a long holiday, the departure time tends to be concentrated in the first half of the holiday.

\section{Analysis of departure times for different charge combinations}

Scenario $S_{0}$ is the reference scenario, and scenarios $S_{1}-S_{7}$ are strategies that combine road toll at different departure times, as detailed in Table 1. Figure 13a,b describe the departure time changes for the short and long vacation models in each scenario. Figure $14 \mathrm{a}, \mathrm{b}$ describe changes in the departure time in each scenario compared with the reference scenario for different travel distances.

It can be seen in Figure 13 that, compared with the reference scenario $S_{0}$, the proportion of departure times on the first day of a holiday generally decreases, but different pricing scenarios have different effects on regulating the proportion of departure times of different holiday lengths. 
(1) When the charge remains unchanged before the holiday (i.e., scenarios $S_{1}-S_{7}$ ):

(1) $S_{1}$ is the strategy that charges throughout the entire holiday. The first-day departure rate of the short holiday model decreases by $4.64 \%$, mainly shifting to a pre-holiday departure (an increase of $7.58 \%$ ). In the long vacation model, the rate of first-day departure increases by $10.27 \%$, the pre-vacation departure rate increases by $8.3 \%$, and the rate of departure on other days of the vacation decreases significantly (by 16.56\%). It can be seen that when the full price is charged at all departure times, the rate of departure on the first day is lower for a short vacation than for a long vacation. This may be because time is more abundant during a long vacation, and travelers are more willing to leave after the start of the holiday. Short holidays are briefer, and travelers prefer to start holiday travel ahead of time if there are no toll-free policy benefits.

(2) $\quad \mathrm{S}_{2}$ is a time-sharing free strategy (i.e., the peak day of the holiday is not free, but the off-peak days of the holiday are free). The results show that the first day of departure has the greatest change in proportion, decreasing by $9.98 \%$ and $3.12 \%$ for the short and long holiday models, respectively, and the decreased proportion is mainly transferred to other days of the holiday ( $6.24 \%$ and $2.73 \%$, respectively). When the full price is applied before the holiday, adjusting the fee (from free to full price) on the first day of the holiday (peak day) can divert travelers to an off-peak day.

(3) $\mathrm{S}_{3}$ is the half-price holiday strategy, and it can be seen that the first-day departure rate of the short vacation model decreases by $3.4 \%$, while that of the long vacation model increases by $3.85 \%$. In the long vacation model, a $50 \%$ discount is implemented on the 1 st-5th days of the vacation, and the fee is waived in full on the 5th-7th days, which increases the probability of departure on the 5 th-7th day of the vacation by $4.35 \%$. It can be seen that the half-price charging scenario $S_{3}$ has a similar effect to the current full-price scenario $S_{0}$ and has no notable effect on changing the proportion of departures on the first day.

(2) When the charge changes before the holiday (i.e., scenarios $S_{4}-S_{7}$ ):

(1) $S_{4}$ and $S_{5}$ are scenarios in which half-price charges are implemented before the holiday: $\mathrm{S}_{4}$ is a time-sharing discount (i.e., half-price discount before and on the first day of the holiday, free on other days of the holiday), and $\mathrm{S}_{5}$ is a peak avoidance discount strategy (i.e., charging at full price on the first day of the holiday and applying a 50\% discount before and on off-peak days of the holiday). The proportion of departures on the first day in the short vacation model under $S_{4}$ and $S_{5}$ decreases by $7.23 \%$ and $9.56 \%$, respectively. The difference between $S_{4}$ and $S_{5}$ in the long vacation model, with the former leading to a slight drop (by 1.65\%) on the first day and the latter causing a slight rise (by $1.38 \%$ ) on the first day, may be explained by the psychological prospect theory that people tend to be more sensitive to losses ( $S_{5}$ applies a discount, but travelers are still charged overall).

$\mathrm{S}_{6}$ and $\mathrm{S}_{7}$ are free pre-holiday scenarios, in which $\mathrm{S}_{6}$ applies a toll-free peak avoidance strategy (i.e., the first day of the holiday peak is full price, while the pre-holiday and holiday off-peak days are free), and $S_{7}$ is a toll-free strategy for all departure times. Under $S_{6}$ and $\mathrm{S}_{7}$, the proportion of departures on the first day in the short holiday model falls by $14.18 \%$ and $4.68 \%$, respectively, and that in the long vacation model decreases by $4.13 \%$ and $2.56 \%$. The rate of decline in the proportion of first-day departures is lower for strategy $S_{7}$ than that for $S_{6}$, and the proportion of each departure time for $S_{7}$ is relatively balanced.

(3) In $\mathrm{S}_{5}$ and $\mathrm{S}_{6}$, the discount before the holiday is doubled. As the pre-holiday discount increases, the proportion of first-day departures under the $\mathrm{S}_{6}$ scenario decreases to a greater extent than that under the $\mathrm{S}_{5}$ scenario; the first-day departures decrease by $14.18 \%$ and $4.13 \%$ for the short vacation and long vacation models, respectively. 
Therefore, if the pre-holiday fee is not adjusted, significantly raising the fee on the first day of the holiday compared with that on the other vacation days is the most effective (for example, the decrease in first-day departures is greater under $S_{2}$ than those under $S_{3}$ and $S_{1}$ ). If the pre-holiday fees are adjusted, raising the fees on the first day compared with the pre-holiday fees has a stronger effect on reducing the first-day departure probability (e.g., $S_{6}>S_{7}$ ). Furthermore, the strategy of adjusting pre-holiday fees is better for reducing the probability of first-day departures (e.g., $S_{6}>S_{2}$ ).

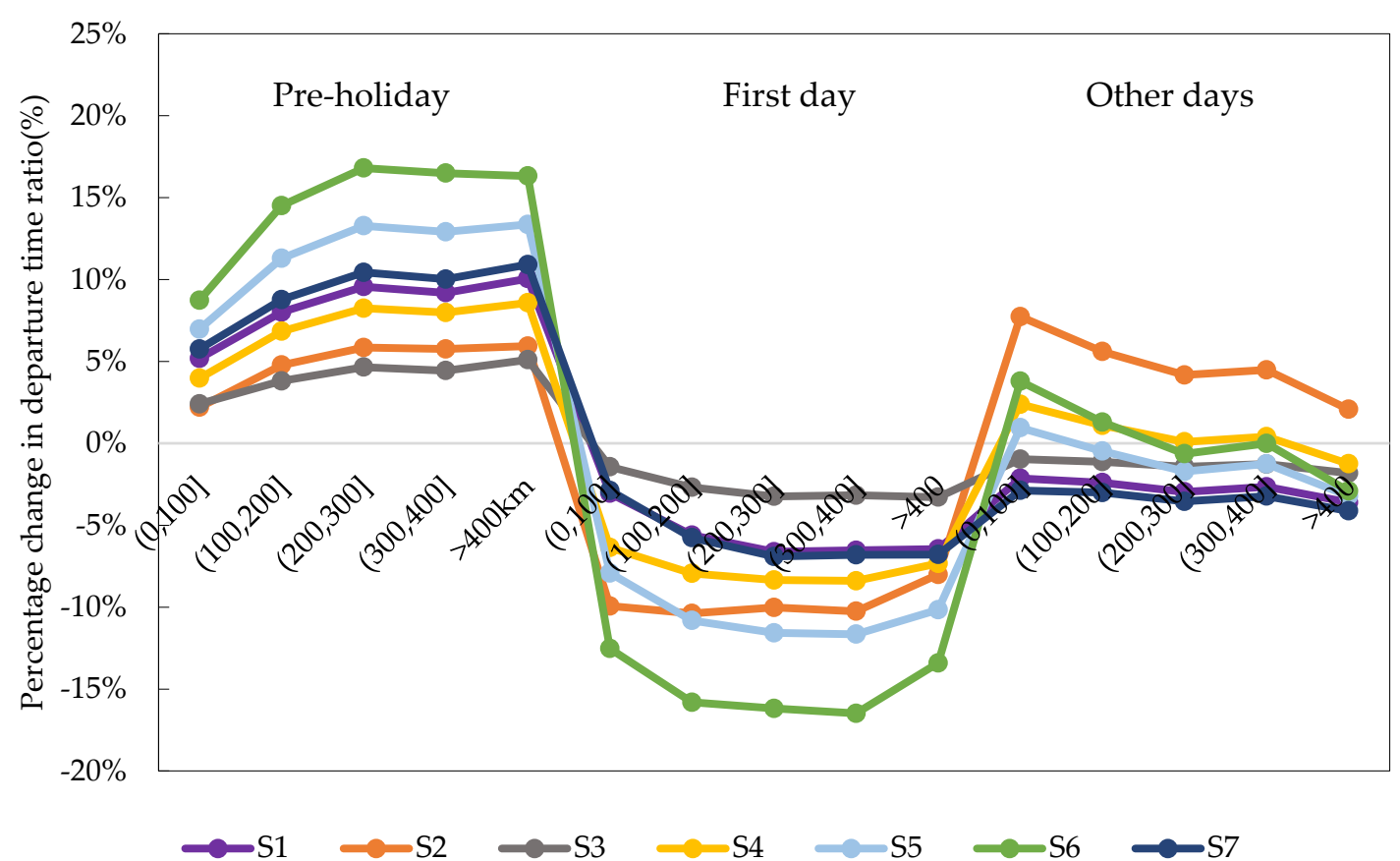

(a) Short vacation model

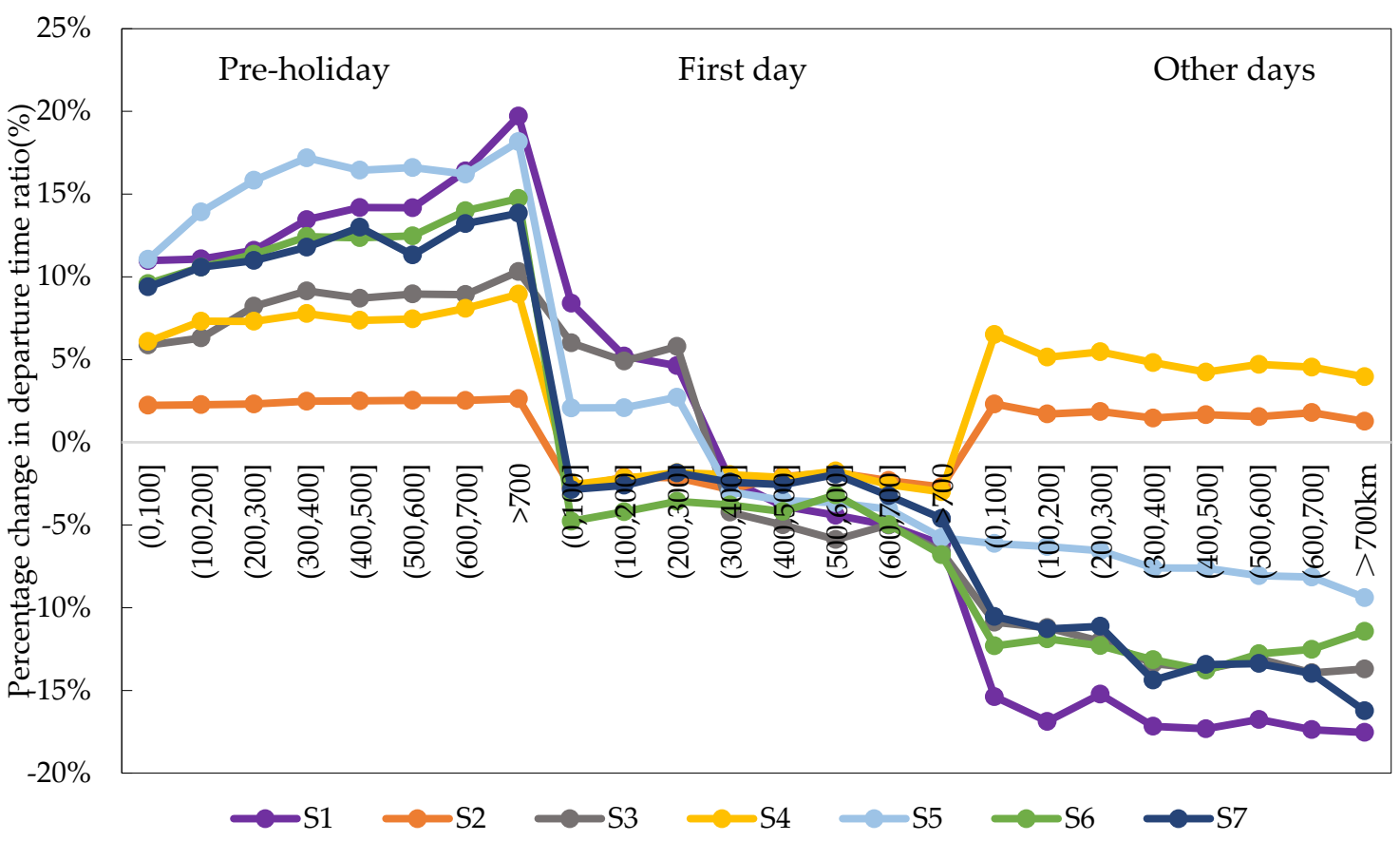

(b) Long vacation model

Figure 14. Probability variation of departure time at different distances and charging scenarios based on $\mathrm{S}_{0}$. 
Figure 14 describes the change rates of the departure times in the short and long vacation models for different distances compared with the reference scenario $\mathrm{S}_{0}$. As can be seen in the diagram, as the travel distance increases, the regulation effect of the highway toll strategy on the departure time changes.

(1) First, the rate of change in departures before the vacation is positive, and it gradually increases as travel distance increases. The rate of change in the short vacation model markedly increases when the travel distance is more than 100 and $400 \mathrm{~km}$, while that in the long vacation model substantially increases when it is more than 300 and $700 \mathrm{~km}$.

(2) Second, with the increase in travel distance, the change rate of departure on the first day of the holiday generally decreases. When the travel distance is greater than $100 \mathrm{~km}$, the sensitivity of the short holiday model is higher and increases slowly with the increase in distance. For the long vacation model, for distances of less than $300 \mathrm{~km}$, the change rate of first-day departures shows polarization: the change rates of $S_{1}, S_{3}$ and $S_{7}$ scenarios are positive (the rate increases on the first day), and the change rates of $S_{2}, S_{4}, S_{5}$ and $S_{6}$ scenarios are negative (the rate decreases on the first day). This indicates that different charging scenarios for travel distances of less than $300 \mathrm{~km}$ have different regulating effects on the proportion of first-day departures. When the travel distance is greater than $300 \mathrm{~km}$, the change rate is negative. Compared with the reference scenario, the first-day departure rate decreases, and then it gradually increases with increasing travel distance.

(3) Furthermore, the sensitivity of the short vacation model for distances of less than $100 \mathrm{~km}$ is the strongest, which indicates that the charging strategy can increase the proportion of departures on other days for short-distance travel. When the distance is over $100 \mathrm{~km}$, the rate of change is either positive or negative, indicating that the proportion of departures on other days of the holiday increases or decreases, and it decreases as travel distance increases. In the long holiday model, the change rate of departures on other days generally decreases with the increase in travel distance, among which the $\mathrm{S}_{2}$ and $\mathrm{S}_{4}$ charging scenarios significantly increase the proportion of departures on other days.

\section{Conclusions}

This paper focuses on the problem of highway traffic congestion caused by the concentration of departure times on holidays. Taking holiday car travelers as the research object, short vacation and long vacation models were established. This paper explores the influence of the road toll policy on the departure time decision-making behavior for different holiday lengths. The conclusions of this paper are as follows:

(1) According to the analysis results of the questionnaire data, regardless of whether the holiday is short or long, the proportion of departures on the first day of a holiday is significantly higher than that on other days under the current policy of free expressway passage, with $62.3 \%$ and $49.6 \%$ of departures occurring on the first day for short and long holidays, respectively. The departure time distribution of different ages, frequencies of visits to scenic spots, travel ranges and travel distances substantially differ for different holiday lengths.

(2) According to the calibration results of the model, travel time, tourist group, the number of visits, travel range, travel time, previous departure time, monthly income, occupation, age and fees applied to different departure times have significant influences on the departure times of holiday travelers. The calibration results show that the effects of individual influencing factors differ between short holidays and long holidays.

(1) The inclination to travel on the first day of the holiday is lower for travelers in larger groups and those with more traveling experience and higher monthly income. 
Travelers aged 18-44 tend to travel on the first day of a short holiday and on the 2nd-4th days of a long holiday.

(3) Travelers on a short holiday with family or friends tend to travel before the holiday, while the influence of the relationship with other tourists is not significant in the long holiday model.

(4) City or suburban travelers tend to travel on days other than the first day of short holidays, but they do not have this tendency on long holidays.

(5) The longer the travel time for a short holiday, the greater the inclination to depart before the holiday, while there is no such inclination before a long holiday because of the abundance of time.

(3) When the travel duration is $\geq 2$ days in the short vacation model and $\geq 4$ days in the long vacation model, travelers are sensitive to the travel time, and there is a greater impact on the probability of departure before the holiday.

(4) Generally speaking, with the increase in road fee concessions, travelers prefer to choose a time with a more favorable price. The effects of various charging schemes on the proportion of departure times are different between the two models. First, in the short vacation model, the greater the pre-vacation fee discount, the greater the impact on the pre-vacation departure probability, while the discount has less influence in the long vacation model. Second, the impact of the first-day holiday fees on the probability of the first-day departure is weak in the short holiday model, while the impact is not significant in the long holiday model. In addition, charges on other days have a greater impact on departures in the long vacation model compared with short vacations.

(5) Finally, through the analysis of scenarios that combine different road toll strategies, the road toll is found to be an effective measure to regulate the departure time choice behavior of travelers during holidays.

(1) If the pre-holiday fee is not adjusted, significantly raising the holiday peak charge above the price on other days is a more effective strategy (such as the $\mathrm{S}_{2}$ time-sharing free strategy), and this effect is stronger for short holidays than long holidays.

(2) If the pre-holiday fee is adjusted, the strategy of charging more on the first day of a holiday than before the holiday is more effective in reducing the first-day trip rate (such as the $\mathrm{S}_{6}$ strategy of free off-peak travel), and the effect is greater for short holidays than long holidays.

(3) In addition, the strategy of adjusting pre-holiday fees is more effective than that of not adjusting pre-holiday fees in reducing the rate of first-day departures. The effectiveness of the road toll policy varies among different travel distances. For short vacations, the effect of this pricing scheme is greater for travel distances between 100 and $400 \mathrm{~km}$, and for long vacations, the effect is strongest for distances between 300 and $700 \mathrm{~km}$.

The conclusions of this paper can provide a reference for establishing effective road passenger flow diversion and holiday vacation time systems on the first day of holidays. Based on the above conclusions, this paper proposes the following suggestions:

(1) For a three-day short holiday, the strategy of offering free time-sharing or off-peak travel can be adopted to convince tourists to adjust their departure times.

(2) For a seven-day long holiday, because the effect of adjusting tolls is weaker for a long holiday than for a short holiday, it may be possible to divide the seven-day holiday into two three-day or five-day holidays so as to reduce the length of the holiday; then, the best approach to adjusting fees can be explored. 
The limitation of this study is that the selected model is relatively simple. As the assumptions of MNL model structure have IIA (Independence of Irrelevant Alternatives) characteristics, this may cause the interaction between alternatives to be ignored, which may lead to deviation of partial elastic results. Therefore, we can try to use other models to explore more deeply, such as other discrete choice models without IIA characteristics, or models more suitable for decision-makers' bounded rationality psychology. At the same time, we can further consider the influence of travel time perceiving or value and other factors, and compare and study the departure time choice characteristics of other transportation modes. In addition, tourism is an activity that is largely based on a travel sequence. The activities between various tourist destinations affect each other and are related to the choice of departure time. In the future, we can further explore the influence of road pricing policies on the combined choice of travel destination and departure time.

Author Contributions: The individual responsibilities and contribution of the authors are listed as follows: H.Z. and Y.H. conceived and designed the research; Y.H. and W.L. devised the questionnaire; H.Z. developed the model and wrote the paper; H.G. guided the research process and revised the manuscript; H.Z. and W.L. performed the analysis of the sample and helped edit the manuscript. All authors have read and agreed to the published version of the manuscript.

Funding: This research was funded by the National Natural Science Foundation of China (No. 71971005) and the Beijing Municipal Natural Science Foundation (No.8202003).

Acknowledgments: The authors are very grateful to all the participants who filled in the questionnaire. We would like to thank the anonymous reviewers for their helpful comments and suggestions, which improved the quality greatly of this paper.

Conflicts of Interest: The authors declare no conflict of interest.

\section{References}

1. Han, Y.; Zhang, T.; Wang, M. Holiday travel behavior analysis and empirical study with Integrated Travel Reservation Information usage. Transp. Res. Part A Policy Pr. 2020, 134, 130-151. [CrossRef]

2. Bao, Y.; Xiao, F.; Gao, Z.; Gao, Z. Investigation of the traffic congestion during public holiday and the impact of the toll-exemption policy. Transp. Res. Part B Methodol. 2017, 104, 58-81. [CrossRef]

3. Zhu, H.; Guan, H.; Han, Y.; Li, W. A Study of Tourists' Holiday Rush-Hour Avoidance Travel Behavior Considering Psychographic Segmentation. Sustainability 2019, 11, 3755. [CrossRef]

4. Yang, G.; Yang, G.; Zhang, T. Spatial-temporal response patterns of tourist flow under entrance tourist flow control scheme. Tour. Manag. 2021, 83, 104246. [CrossRef]

5. Fu, S.; Gu, Y. Highway toll and air pollution: Evidence from Chinese cities. Jour. Env. Eco. Mana. 2017, 83, 32-49. [CrossRef]

6. AMAP. Travel Report on National Day of 2017; Travel Report AMAP: Beijing, China, 2017; pp. 1-20.

7. AMAP. Travel Report on National Day of 2018; Travel Report AMAP: Beijing, China, 2018; pp. 1-15.

8. Lin, X.; Susilo, Y.O.; Shao, C.F.; Liu, C. The Implication of Road Toll Discount for Mode Choice: Intercity Travel during the Chinese Spring Festival Holiday. Sustainability 2018, 10, 2700. [CrossRef]

9. Wang, B.; Shao, C.; Li, J.; Weng, J.; Ji, X. Holiday travel behavior analysis and empirical study under integrated multimodal travel information service. Transp. Policy 2015, 39, 21-36. [CrossRef]

10. Han, Y.; Han, Y.; Gong, H.; Zhang, T. Spatial-Temporal Response Patterns of Tourist Flow under Real-Time Tourist Flow Diversion Scheme. Sustainability 2020, 12, 3478. [CrossRef]

11. Wen, C.-H.; Yeh, Y. Modeling air travelers' choice of flight departure and return dates on long holiday weekends. J. Air Transp. Manag. 2017, 65, 220-225. [CrossRef]

12. Wachs, M. Then and now: The evaluation of congestion pricing in transportation and where we stand today. Transp. Res. Rec. J. Res. Board. 2005, 34, 63-72.

13. Takahashi, H.; Mabuchi, K.; Xing, J.; Kameoka, H.; Sato, H. Examining effects of TDM with toll discount on mitigation of expressway traffic congestion. Proc. East. Asia Soc. Trans. Stud. 2008, 2007, 76.

14. Tillema, T.; Ben-Elia, E.; Ettema, D.; Van Delden, J. Charging versus rewarding: A comparison of road-pricing and rewarding peak avoidance in the Netherlands. Transp. Policy 2013, 26, 4-14. [CrossRef] 
15. IEDAH. Historic Toll-Discount in Japan's Intercity Expressway for Economic Stimulation: Its Four Aspects, Results, and Points at Issue. In Proceedings of the 8th International Conference of Eastern Asia Society for Transportation Studies, Kota, Indonesia, 16-19 November 2009; Volume 7, p. 75.

16. Takahashi, H.; Kameoka, H.; Mabuchi, K.; Sato, H.; Xing, J. Examining effects of TDM with toll discount on mitigation of expressway traffic congestion. In Proceedings of the 7th International Conference of Eastern Asia Society for Transportation Studies, Dalian, China, 24-27 September 2007; p. 76.

17. Li, J.; Weng, J.; Shao, C.; Guo, H. Cluster-Based Logistic Regression Model for Holiday Travel Mode Choice. Procedia Eng. 2016, 137, 729-737. [CrossRef]

18. Asakura, Y.; Iryo, T. Analysis of tourist behaviour based on the tracking data collected using a mobile communication instrument. Transp. Res. Part A Policy Pract. 2007, 41, 684-690. [CrossRef]

19. Kaplan, S.; Manca, F.; Nielsen, T.A.S.; Prato, C.G. Intentions to use bike-sharing for holiday cycling: An application of the Theory of Planned Behavior. Tour. Manag. 2015, 47, 34-46. [CrossRef]

20. Yang, L.; Shen, Q.; Li, Z. Comparing travel mode and trip chain choices between holidays and weekdays. Transp. Res. Part A Policy Pract. 2016, 91, 273-285. [CrossRef]

21. Cranenburgh, S.V.; Chorus, C.G.; Wee, B.V. Vacation behavior under high travel cost conditions-A stated preference of revealed preference approach. Tour. Manag. 2014, 43, 105-118. [CrossRef]

22. Yang, Y.; Fik, T.; Zhang, J. Modeling sequential tourist flows: Where is the next destination? Ann. Tour. Res. 2013, 43, 297-320. [CrossRef]

23. Huybers, T. Domestic tourism destination choices-A choice modelling analysis. Int. Jour. Tour. Res. 2003, 5, 445-459. [CrossRef]

24. Wu, L.; Zhang, J.; Fujiwara, A. A Tourist's Multi-Destination Choice Model with Future Dependency. Asia Pac. J. Tour. Res. 2012, 17, 121-132. [CrossRef]

25. Lamondia, J.; Bhat, C.R.; Hensher, D.A. An annual time use model for domestic vacation travel. J. Choice Model. 2008, 1, 70-97. [CrossRef]

26. Wang, B.; Shao, C.; Li, J.; Zhao, D.; Meng, M. Investigating the interaction between the parking choice and holiday travel behavior. Adv. Mech. Eng. 2015, 7. [CrossRef]

27. Lim, X.; Shao, C.; Dong, C.; Wang, S. The behavior characteristics of inter-city travel under the implication of expressway toll-free policy during holiday. J. Transp. Sys. Eng. Inf. Technol. 2019, 19, 247-254.

28. Dargay, J.M.; Clark, S. The determinants of long distance travel in Great Britain. Transp. Res. Part A Policy Pract. 2012, 46, 576-587. [CrossRef]

29. Yang, L.; Zheng, G.; Zhu, X. Cross-nested logit model for the joint choice of residential location, travel mode, and departure time. Habitat Int. 2013, 38, 157-166. [CrossRef]

30. Ben-Akiva, M.; Lerman, S.R. Discrete Choice Analysis: Theory and Application to Travel Demand; MIT Press: Cambridge, UK, 1985.

31. Haider, W.; Ewing, G.O. A model of tourist choices of hypothetical Caribbean destinations. Leis. Sci. 1990, 12, 33-47. [CrossRef]

32. Morley, C.L. Experimental destination choice analysis. Ann. Tour. Res. 1994, 21, 780-791. [CrossRef]

33. Böhler, S.; Grischkat, S.; Haustein, S.; Hunecke, M. Encouraging environmentally sustainable holiday travel. Transp. Res. Part A Policy Pract. 2006, 40, 652-670. [CrossRef]

34. Tsourgiannis, L.; Delias, P.; Polychronidou, P.; Karasavvoglou, A.; Valsamidis, S. Profiling Tourists who have Holidays in the Region of Eastern Macedonia and Thrace in Greece. Procedia Econ. Financ. 2015, 33, 450-460. [CrossRef]

35. Shailes, A.; Senior, M.L.; Andrew, B.P. Tourists' travel behaviour in response to congestion: The case of car trips to Cornwall, United Kingdom. J. Transp. Geogr. 2001, 9, 49-60. [CrossRef]

36. Guan, H.; Shao, J. Model of Traffic Behavior Analysis for Self-driving Travel. Urban Trans. 2005, 3, 63-66.

37. Cools, M.; Moons, E.; Wets, G. Investigating Effect of Holidays on Daily Traffic Counts: Time Series Approach. Transp. Res. Rec. J. Res. Board. 2007, 2019, 22-31. [CrossRef]

38. Cools, M.; Moons, E.; Wets, G. Investigating the Variability in Daily Traffic Counts through use of ARIMAX and SARIMAX Models: Assessing the Effect of Holidays on Two Site Locations. Transp. Res. Rec. J. Res. Board. 2009, 2136, 57-66. [CrossRef]

39. Cools, M.A.W. Assessing the Impact of Public Holidays on Travel Time Expenditure: Differentiation by Trip Motive. Transp. Res. Rec. J. Res. Board. 2010, 2157, 29-37. [CrossRef] 
40. Mussalam, G.Q.; Tajeddini, K. Tourism in Switzerland: How perceptions of place attributes for short and long holiday can influence destination choice. J. Hosp. Tour. Manag. 2016, 26, 18-26. [CrossRef]

41. Zhang, C.; Bao, J. Impact of holiday policy upon tourist flow in world heritage site: Taking Wulingyuan of Hunan as a case. Geog. Res. 2007, 026, 1295-1303.

42. Lin, X.-M.; Shao, C.-F.; Qian, J.-P.; Zhang, Y.-D. Evolution dynamic of the expressway toll-free policy impact on the mode choice in a bimodal transportation network during holidays. Adv. Mech. Eng. 2017, 9. [CrossRef]

43. Huang, C.; Wu, J.; Zhang, F. Impact factors of travel intention during the toll road being free on the major holidays. J. Transp. Sys. Eng. Inf. Technol. 2013, 13, 161-168.

44. Qian, J.; Wang, D.; Niu, Y. Changes in City Residents' Support for the National Highway Toll-free Policy and Their Travel Behavior: The Case of Suzhou. Tour. Trib. 2015, 30, 50-61.

45. Albert, G.; Mahalel, D. Congestion tolls and parking fees: A comparison of the potential effect on travel behavior. Transp. Policy 2006, 13, 496-502. [CrossRef]

46. Steiner, T.; Bristow, A.L. Road pricing in National Parks: A case study in the Yorkshire Dales National Park. Transp. Policy 2000, 7, 93-103. [CrossRef]

47. Karlström, A.; Franklin, J.P. Behavioral adjustments and equity effects of congestion pricing: Analysis of morning commutes during the Stockholm Trial. Transp. Res. Part A Policy Pract. 2009, 43, 283-296. [CrossRef]

48. Ramos, G.M.; Daamen, W.; Hoogendoorn, S. A State-of-the-Art Review: Developments in Utility Theory, Prospect Theory and Regret Theory to Investigate Travellers' Behaviour in Situations Involving Travel Time Uncertainty. Transp. Rev. 2014, 34, 46-67. [CrossRef]

49. Jou, R. Modeling the impact of pre-trip information on commuter departure time and route choice. Transp. Res. Part B Methodol. 2001, 35, 887-902. [CrossRef]

50. Jou, R.-C.; Kitamura, R.; Weng, M.-C.; Chen, C.-C. Dynamic commuter departure time choice under uncertainty. Transp. Res. Part A Policy Pract. 2008, 42, 774-783. [CrossRef]

51. Small, K.A. The Scheduling of Consumer Activities: Work Trips. Am. Econ. Rev. 1982, 72, 467-479.

52. Polak, J.; Jones, P. A Tour-Based Model of Journey Scheduling under Road Pricing. In Proceedings of the 73rd Annual Meeting of the Transportation Research Board, Washingtona, DC, USA, 1994.

53. Thorhauge, M.; Cherchi, E.; Rich, J. How flexible is flexible? Accounting for the effect of rescheduling possibilities in choice of departure time for work trips. Transp. Res. Part A Policy Pract. 2016, 86, 177-193. [CrossRef]

54. Bhat, C.R.; Steed, J.L. A continuous-time model of departure time choice for urban shopping trips. Transp. Res. Part B Methodol. 2002, 36, 207-224. [CrossRef]

55. Waerden, P.V.D.; Janssens, D.; Silva, A.N.R.D. The influence of parking facility characteristics on car drivers' departure time decisions. Transp. Res. Procedia 2017, 25, 4058-4067. [CrossRef]

56. Choo, S.; Mokhtarian, P. Individual responses to congestion policies: Modeling the consideration of factor-based travel-related strategy bundles. KSCE J. Civ. Eng. 2012, 16, 822-834. [CrossRef]

57. Engelson, L.; Fosgerau, M. Scheduling preferences and the value of travel time information. Transp. Res. Part B Methodol. 2020, 134, 256-265. [CrossRef]

58. Saleh, W.; Farrell, S. Implications of congestion charging for departure time choice: Work and non-work schedule flexibility. Transp. Res. Part A Policy Pract. 2005, 39, 773-791. [CrossRef]

59. Sasic, A.; Habib, K.N. Modelling departure time choices by a Heteroskedastic Generalized Logit (Het-GenL) model: An investigation on home-based commuting trips in the Greater Toronto and Hamilton Area (GTHA). Transp. Res. Part A Policy Pract. 2013, 50, 15-32. [CrossRef]

60. Arian, A.; Ermagun, A.; Zhu, X.; Chiu, Y.-C. An Empirical Investigation of the Reward Incentive and Trip Purposes on Departure Time Behavior Change. Adv. Transp. Policy Plan. 2018, 1, 145-167. [CrossRef]

61. He, S.Y. Does flexitime affect choice of departure time for morning home-based commuting trips? Evidence from two regions in California. Transp. Policy 2013, 25, 210-221. [CrossRef]

62. Ben-Elia, E.; Ettema, D. Carrots versus sticks: Rewarding commuters for avoiding the rush-hour-A study of willingness to participate. Transp. Policy 2009, 16, 68-76. [CrossRef]

63. Ben-Elia, E.; Ettema, D. Rewarding rush-hour avoidance: A study of commuters' travel behavior. Transp. Res. Part A Policy Pract. 2011, 45, 567-582. [CrossRef]

64. Zhang, Z.; Fujii, H.; Managi, S. How does commuting behavior change due to incentives? An empirical study of the Beijing Subway System. Transp. Res. Part F Traffic Psychol. Behav. 2014, 24, 17-26. [CrossRef] 
65. Pluntke, C.; Prabhakar, B. INSINC: A Platform for Managing Peak Demand in Public Transit. Journeys 2013, 9, 31-38.

66. Currie, G. Exploring the Impact of the "Free Before 7" Campaign on Reducing Overcrowding on Melbourne's Trains; 32nd Australasian Transport Research Forum: Auckland, New Zealand, 2009.

67. Abkowitz, M.D. An analysis of the commuter departure time decision. Transportation 1981, 10, $283-297$. [CrossRef]

68. Bradley, M.; Bowman, J.L.; Griesenbeck, B. SACSIM: An applied activity-based model system with fine-level spatial and temporal resolution. J. Choice Model. 2010, 3, 5-31. [CrossRef]

69. Yang, G.; Li, W.; Wei, S.; Zhang, T. Research on Passenger's Travel Mode Choice Behavior Waiting at Bus Station Based on SEM-Logit Integration Model. Sustainability 2018, 10, 1996. [CrossRef]

70. Lee-Gosselin, M.E.H. The scope and potential of interactive stated response data collection methods: Household Travel Surveys. In Transportation Research Board Proceedings 10; Transportation Research Board: Washington, DC, USA, 1996.

Publisher's Note: MDPI stays neutral with regard to jurisdictional claims in published maps and institutional affiliations.

(C) 2020 by the authors. Licensee MDPI, Basel, Switzerland. This article is an open access article distributed under the terms and conditions of the Creative Commons Attribution (CC BY) license (http://creativecommons.org/licenses/by/4.0/). 